TIAGO ANTONIO DE SOUZA

\title{
Análise das alterações genéticas em exomas de camundongos
}

Tese apresentada ao Programa de PósGraduação Interunidades em Biotecnologia da Universidade de São Paulo, Instituto Butantan e Instituto de Pesquisas Tecnológicas para obtenção do Título de Doutor em Biotecnologia.

Área de concentração: Biotecnologia

Orientador: Prof. Dr. Carlos F. M. Menck

Coorientador: Dra. Silvia M. G. Massironi

Versão original.

São Paulo 


\section{RESUMO}

DE SOUZA TA. Análise das alterações genéticas em exomas de camundongos. 2018. 155 f. [Tese (Doutorado em Biotecnologia)]. São Paulo: Instituto de Ciências Biomédicas, Universidade de São Paulo; 2018.

Camundongos são modelos valiosos para o entendimento dos processos e mecanismos moleculares e fisiológicos em mamíferos. A maioria do nosso conhecimento sobre esses processos e mecanismos vem de experimentos realizados com camundongos de linhagens isogênicas. Essas linhagens, criadas normalmente por sucessivos cruzamentos irmão-irmã, surgiram no início do século XX visando reduzir a interferência da variabilidade genética, aumentando a reprodutibilidade dos experimentos. Caracterizar o background genético das linhagens isogênicas permite não só traçar possíveis relações de parentesco entre linhagens, mas também permite o controle genético oriundo de possíveis contaminações e mutações espontâneas que possam surgir na população. Além das linhagens isogênicas, os camundongos mutantes também são importantes como modelos para o estudo de doenças humanas. O uso desses modelos murinos permite a elucidação e associação de fatores genéticos a manifestações fenotípicas diversas, como síndromes hereditárias e predisposições a doenças. Esses mutantes podem ser gerados por uma abordagem de varredura de mutagênese pelo agente mutagênico ENU, que inclui a caracterização de fenótipos interessantes e a busca pelas mutações causativas induzidas. O presente trabalho teve como objetivo utilizar o sequenciamento completo de exomas para caracterizar o background genético das linhagens isogênicas C57BL/6ICBI e BALB/CICBI, mantidas há quase 20 anos no Brasil e distribuídas pelo ICB-USP a pesquisadores de todo país. O trabalho também usou o sequenciamento de nova geração (NGS) para a busca das mutações causadores de fenótipo em um grupo de sete mutantes induzidos por ENU oriundos de uma varredura prévia. Através da aplicação de uma estratégia de análise de dados e filtragem de mutações foi possível encontrar mutações candidatas com alto potencial de impacto para todos os mutantes avaliados, validadas por sequenciamento Sanger. Os genes afetados pelas mutações encontradas indicam que os mutantes possam se tornar interessantes modelos para o estudo de doenças neuromusculares e neurológicas. A avaliação do exoma das linhagens $\mathrm{C} 57 \mathrm{BL} / 6 \mathrm{ICBI}$ e BALB/CICBI descartou a possibilidade de contaminação das colônias com outras linhagens, e revelou similaridades relacionadas com o parentesco das sublinhagens brasileiras em relação a linhagens gold-standard. As informações obtidas serão uma fonte importante de informação no planejamento e análise dos resultados obtidos com o uso tanto dos mutantes quanto com as linhagens fornecidas pelo Biotério do Departamento de Imunologia ao ICB a instituições de todo o Brasil.

Palavras-chave: Sequenciamento genético. Bioinformática. Camundongos. Mutações Induzidas. Mutagênese. 


\section{ABSTRACT}

DE SOUZA TA. Analysis of genetic alterations in mice exomes. 2018. 155 f. [Ph.D. Thesis (Biotechnology)]. São Paulo: Instituto de Ciências Biomédicas, Universidade de São Paulo; 2018.

Mice are valuable models for the comprehension of molecular processes and underlying physiological mechanisms in mammals. Most of the knowledge about those processes came from experiments with isogenic mice. Those strains, arose in the 1900's by successive inbreeding, are very important as they reduce genetic variability across the experiments increasing reproducibility. Isogenic lineages are kept as isolated colonies in animal facilities and supplied to researchers, as they needed. Thus, is possible to trace relationships among strains all over the world using the characterization of their genetic backgrounds. It is also possible to detect putative contaminations and spontaneous mutations which can arise in the populations. Mutant mice are also important tools as human disease models, allowing associations between genetic factors and phenotypes. Those mutants could be generated in forward genetics approaches by screenings using mutagens as ENU. The aims of this work were to characterize the genetic background of two mouse strains used at ICB-USP $\mathrm{C} 57 \mathrm{BL} / 6 \mathrm{ICBI}$ and $\mathrm{BALB} / \mathrm{CICBI}$ - and to find causative mutations of seven mutants generated by a previous ENU-mutagenesis screening. We used whole-exome sequencing followed by resequencing data-analysis approaches to detect SNVs for both isogenic strains and mutants. Exome evaluation of isogenic strains $\mathrm{C} 57 \mathrm{BL} / 6 \mathrm{ICBI}$ and $\mathrm{BALB} / \mathrm{ClCBI}$ did not reveal any evidence for cross-contamination and provided insightful details related to other strains and substrains. A specific filtering strategy was applied to select candidates for phenotypecausative mutations in the seven ENU-induced mutants. We are able to select candidates for all mutants at a high global Sanger validation rate when considering only the main candidates for each mutant. Considering affected genes and phenotypes all mutants have potential to become interesting mouse models for human diseases. Taken together, our results are a reliable and confident source of genetic information for experimental analysis for researchers who use isogenic strains provided by animal facility at ICB-USP and research groups interested in further characterization of mutant study neuromuscular, neuronal or development processes using mice as animal models.

Keywords: DNA Sequencing. Bioinformatics. Mice. Induced mutations. Mutagenesis. 


\section{CAPÍTULO 1- SEQUENCIAMENTO COMPLETO DO EXOMA DE CAMUNDONGOS}

\subsection{Introdução}

A compreensão da biologia humana é um dos aspectos principais da própria biologia como ciência. Entendê-la significa melhorar a qualidade de vida em termos de prevenção e tratamento de fatores que afetam a saúde humana. Todo o funcionamento do corpo humano é dependente de maquinarias moleculares codificadas pelo nosso genoma, por suas interações com o microambiente interno fisiológico e também com a influência de todo um macroambiente externo. Dessa forma, o desenvolvimento do ser humano em um organismo envolve uma base genética determinística, que se torna incrivelmente complexa quando consideramos os fatores ambientais. Correlacionar essas bases genéticas - cada vez mais conhecidas devido ao crescente uso das tecnologias de sequenciamento de DNA às características físicas de um indivíduo significa melhorar nossa compreensão sobre o próprio papel das funções moleculares e fisiológicas determinadas pelo nosso genoma na manutenção da vida. Uma melhor compreensão desses mecanismos possibilita, por exemplo, melhores métodos de intervenção para quaisquer tipos de doenças que possam prejudicar o indivíduo e a população humana em geral.

\subsubsection{Panorama geral das relações genótipo-fenótipo em humanos}

Associar uma base genética - ou genótipo - a uma determinada manifestação de uma característica "física" - ou fenótipo - ou seja, compreender a função de um ou mais genes, não é uma tarefa trivial (ANTONARAKIS; BECKMANN, 2006). Essa associação começou a ser compreendida pelos estudos pioneiros realizados por Gregor Mendel, em meados do século XIX, e só redescoberta no início do século XX por William Bateson. Bateson cunhou pela primeira vez o termo "genética" em 1905 e traduziu o trabalho de Mendel para o mundo no livro Mendel's principles of heredity em 1909 (BATESON; MENDEL, 1909). Os conceitos de hereditariedade definidos por Mendel em plantas foram pela primeira vez utilizados no estudo da alcaptonúria em 1902, considerada a primeira doença genética a ser descrita (GARROD, 1902). Teve início então a era da genética humana, abrindo possibilidade para a realização de predições sobre o fenótipo dos indivíduos a partir de suposições de seus genótipos. Essas doenças hereditárias, cujo padrão hereditário estava associado à 
segregação de alelos de genes específicos segundo as leis propostas por Mendel, ficaram conhecidas como síndromes mendelianas. Esses alelos mendelianos, como são conhecidos, são muito raros na população humana, refletindo a baixa incidência das síndromes mendelianas - elas afetam somente cerca de 10 em cada 1000 pessoas no mundo (WHO, 2017¹). Atualmente são conhecidas mais de 5.000 síndromes mendelianas, clinicamente associadas a um padrão de herança por um único gene, por isso denominadas síndromes mendelianas monogênicas ou simplesmente síndromes monogênicas (OMIM, 2017²).

Um dos principais motivos para a euforia da divulgação do sequenciamento do genoma humano, no início do século $X X I$, era a descoberta das sequencias de todos os genes humanos (CROLLIUS et al., 2000). Supunha-se, na época, que o genoma humano poderia conter 100.000 ou mais genes, mas esse número mostrouse quase 5 vezes menor que a maioria das previsões (HGP, 2001; VENTER et al., 2001). Genes que codificam para proteínas correspondem apenas a uma pequena parcela de todo o genoma, em termos de número de pares de bases. Não há dúvidas, portanto, que o sequenciamento do genoma humano trouxe grandes descobertas e informação para o estudo das funções dos genes em relação ao desenvolvimento dos estudos de doenças mendelianas e da própria genética médica em si (HEARD et al., 2010), que iriam surgir ao longo dos anos 2000 até os dias de hoje, em forma de bancos de dados e catálogos.

O catálogo OMIM (ㅁnline Mendelian Inheritance In Man), criado no começo dos anos 1960 por Victor A. McKusick, acumula dados funcionais de todas as síndromes mendelianas e também informações associadas de mais de 15.000 genes (AMBERGER et al., 2015). Apesar da grande quantidade de dados, apenas 3.825 genes com mutações foram associados como causais em relação à um determinado fenótipo clínico (OMIM, 2017³). A grande maioria dos genes - 3.445 está relacionada com doenças e traços monogênicos, enquanto 499 estão associados com susceptibilidade a doenças complexas ou infecções. Apenas 115 genes estão associados a variações benignas em testes laboratoriais - deficiência na lactato desidrogenase $\mathrm{B}$, por exemplo. Apenas 121 genes estão associados a

\footnotetext{
1 World Health Organization, WHO, 27/10/2017: http://www.who.int/genomics/public/geneticdiseases

2 Online Mendelian Inheritance in Man, $\mathrm{OMIM}^{\circledR}$. McKusick-Nathans Institute of Genetic Medicine, Johns Hopkins University (Baltimore, MD), 27/10/2017: https://omim.org/

3 OMIM $^{\circledR}$ Dissected Morbid Map Scorecard, 16/10/2017: https://www.omim.org/statistics/geneMap
} 
doenças genéticas em células somáticas - como a síndrome de McCune-Albright e o gliobastoma multiforme. O número de genes humanos segundo os parâmetros do comitê $\mathrm{HUGO}^{4}$ é de 20.212 genes sendo 19.109 genes classificados como codificadores de proteínas segundo o $\mathrm{HGNC}^{5}$. Considerando esses dados, apenas $18 \%$ dos genes têm até o momento algum tipo de fenótipo clínico associado em humanos, ou seja, são genes cujo impacto fenotípico e papel em doenças hereditárias pode ser inferido com um grau considerável de precisão. Se considerarmos uma definição de gene um pouco mais abrangente, incluindo além de segmentos de DNA que codificam proteínas também outros segmentos que codificam para RNAs longos não codificantes, pseudogenes, pequenos RNAs não codificantes e miRNAs, o número de associações fenotípicas descobertas é ainda menor (ZHANG; LUPSKI, 2015).

O panorama fica um pouco mais complexo ao considerarmos todas as regiões do genoma que não são consideradas como genes que codificam proteínas. Essas regiões não-codificantes perfazem cerca de $98,5 \%$ de todo o genoma humano - e ficaram conhecidas pelo famoso termo "DNA lixo", que se popularizou após o sequenciamento do genoma humano (HEARD et al., 2010). Esse termo se mostrou de fato muito equivocado, principalmente depois dos estudos do projeto ENCODE Encyclopaedia of DNA Elements ${ }^{6}$ - iniciado em 2003. Segundo o ENCODE quase $80 \%$ do genoma possui algum tipo de atividade regulatória, entre mais de 70.000 promotores e quase 400.000 enhancers (ENCODE, 2012). O projeto, ainda em andamento, empregou um vasto conjunto de técnicas de identificação de sequências regulatórias, em mais de 10.000 amostras de linhagens celulares, tecidos, células primárias e células tronco somente em humanos, revelando uma rede de regulação gênica descomunal (ENCODE, 2012; KELLIS et al., 2014). Vários desses elementos possuem uma correspondência estatística a variantes associadas a doenças humanas e constituem uma base essencial para guiar a interpretação dos mecanismos moleculares associados a doenças e processos biológicos (SCHAUB et al., 2012).

\footnotetext{
${ }^{4}$ HUGO - Human Genome Organisation: www.hugo-international.org

${ }^{5}$ HGNC - Hugo Gene Nomenclature Committee, 16/10/2017: https://www.genenames.org/cgibin/statistics

${ }^{6}$ ENCODE - Encyclopaedia of DNA Elements: https://www.encodeproject.org/
} 
No caso de manifestações fenotípicas em que não é possível estabelecer um padrão claro de herança mendeliana, a situação é um pouco mais dramática. $\mathrm{Na}$ tentativa de estabelecer conexões entre variações genotípicas e fenotípicas são utilizadas abordagens chamadas de GWAS - Genome Wide $\underline{\text { Association }}$ Studies (BUSH; MOORE, 2012). Essas abordagens consistem no agrupamento sistemático de indivíduos com um determinado traço fenotípico e a correlação de variantes comuns entre os membros desse grupo com a incidência do fenótipo, seguida pela inferência independente da predisposição associada às variantes detectadas (VISSCHER et al., 2012). Esses estudos envolvem comumente a genotipagem por microarranjos de um grande número de indivíduos, podendo chegar de 10.000 a 100.000 indivíduos (BUSH; MOORE, 2012). A aplicação clínica dessas abordagens tem contribuído muito para a avaliação da heritabilidade e o cálculo dos fatores de risco associados a características complexas, como o câncer (SUD et al., 2017), obesidade (GHOSH; BOUCHARD, 2017), diabetes e esquizofrenia (KURE; ANTONIO, 2017), por exemplo.

No entanto, abordagens do tipo GWAS têm tido um sucesso limitado (PASANIUC et al., 2012) na elucidação das bases genética no contexto molecular, funcional e biológico. Ou seja, a falta de um padrão de heritabilidade interpretável biologicamente em manifestações fenotípicas é mais uma regra do que uma exceção. Mais de $80 \%$ dos indivíduos presentes nos estudos de GWAS até 2016 tinham ancestralidade europeia, revelando um viés preocupante desses estudos (POPEJOY; FULLERTON, 2016). Outros fatores podem também afetar associações com o fenótipo, como os efeitos de segregação conjunta em variantes próximas, epistasia e variações ambientais. Esses fatores também estão associados a taxas de sucesso reduzidas em abordagens GWAS, justificando a relevância do uso de modelos animais (ERMANN; GLIMCHER, 2012).

\subsubsection{Variabilidade genética em populações humanas}

Dado esse panorama de regiões que podem estar diretamente envolvidas em manifestações fenotípicas em humanos é necessário compreender a origem e identificar a quantidade de variações genéticas hereditárias presentes na população humana. Estima-se que dois indivíduos não relacionados compartilhem entre si cerca entre 99,5 e 99,9\% de identidade em seus genomas (LEVY et al., 2007; VENTER et al., 2001). Dessa forma, apenas 0,5\% - ou 15 milhões de bases - 
constituem variações em termos de sequência, tanto polimorfismos quanto variantes raras que podem estar potencialmente associadas a doenças, síndromes mendelianas e predisposições genéticas variadas.

O projeto 1000 Genomes iniciou-se em 2008 com o objetivo de mapear os polimorfismos presentes na população humana através do sequenciamento de indivíduos saudáveis provenientes da América, Europa, África e Ásia. No total 2.504 indivíduos de 26 populações foram sequenciados, incluindo genomas completos, exomas e genotipagem por microarranjos. Mais de 88 milhões de variantes foram encontradas - cerca de 84,7 milhões consistiam apenas de SNPs - Single

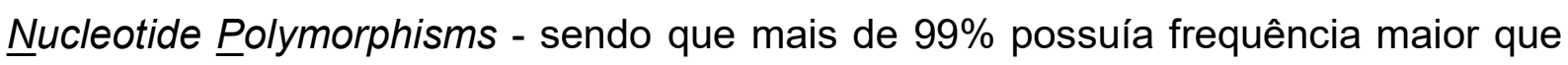
1\% (1000 GENOMES PROJECT et al., 2015). Esse número de variantes é proveniente dos processos mutagênicos espontâneos que originam mutações pontuais em células germinativas a uma taxa estimada de $1 \times 10^{-8}$ nucleotídeos por sítio por geração em humanos. A taxa de mutação somática espontânea em células epiteliais do intestino é cerca de 13 vezes maior do que em células germinativas e por extrapolação cerca de 5 vezes maior em fibroblastos e linfócitos ( $L Y N C H, 2010$ ). Embora as taxas de mutação sejam relativamente baixas, a fixação dessas mutações germinativas pode ser seriamente agravada em populações isoladas, onde a consanguinidade é comum e, portanto, a taxa de síndromes mendelianas é maior (HAMAMY et al., 2011).

De fato, a consanguinidade familiar ainda é um dos fatores que mais colaboram com a caracterização da base genética de doenças mendelianas e a determinação da função dos genes em humanos (CHONG et al., 2015). Em grande parte do mundo essa taxa é menor que 5\%, mas atinge taxas elevadas em algumas regiões - entre $20 \%$ e $50 \%$ no Oriente Médio, norte da África e no sudoeste da Ásia por exemplo - devido principalmente a particularidades culturais e religiosas. A análise dos pedigrees familiares aliado ao acompanhamento clínico permite a inferência do padrão de herança de uma determinada síndrome, restringindo a quantidade de genes que podem estar afetados (HAMAMY, 2012; HAMAMY et al., 2011). Um exemplo marcante no Brasil é a comunidade de Araras, situada no interior do estado de Goiás, onde a incidência de uma doença grave chamada de xeroderma pigmentosum é cerca de 100 vezes maior em comparação com a taxa de incidência estimada no mundo. Essa alta incidência é devido à presença de dois alelos mutantes no gene codificante para a POLH - DNA polimerase eta - ou XPV, 
fixados na população devido a elevada taxa de casamentos consanguíneos entre os moradores da comunidade (MUNFORD, CASTRO et al., 2017).

\subsubsection{O uso de camundongos como modelo animal}

A principal consequência do acúmulo de informações de variantes provenientes dos maiores projetos de genômica humana, como os citados anteriormente, é justamente a dificuldade em conectá-las de forma a compreender a base genética das doenças. Isso acontece porque a genética humana é difícil: estudos de gerações são complicados, os acasalamentos não são pré-definidos e o tempo de uma geração é muito longo. Além disso, o acesso a tecidos é limitado e a genética humana é basicamente observacional e não interventiva. O reflexo dessas questões é a dificuldade em prever que determinadas mutações influenciem e até causem determinado fenótipo. Felizmente, praticamente todas essas limitações são superadas com o uso de modelos animais (ERMANN; GLIMCHER, 2012).

Um dos modelos animais mais usados é o camundongo, cujo genoma, anatomia e fisiologia são muito similares ao homem. Homens e camundongos têm uma linguagem similar de regulação gênica e compartilham cerca de $80 \%$ das sequências codificadoras de proteínas ( $\mathrm{CHURCH}$ et al., 2009). Camundongos também possuem período de gestação e idade fértil bem menores que o homem, além de serem dóceis e com custo de manutenção relativamente baixo. Além de todos esses motivos, a maioria das técnicas de genética clássica e de genética molecular estão muito bem estabelecidas em camundongos, facilitando a manipulação em nível molecular dos genes-alvo (WEYDEN et al., 2011).

$\mathrm{O}$ uso de camundongos como modelo animal (Figura 1.1) se relaciona principalmente a difusão do uso de linhagens isogênicas de camundongos (Figura 1.1A e B), que se destacam pela maior similaridade genética entre seus membros. As estratégias de cruzamento para a obtenção de linhagens isogênicas consistem basicamente de sequências de cruzamentos irmão-irmã. Uma linhagem é considerada isogênica quando ocorre o processo de acasalamento irmão-irmã por pelo menos 20 gerações sequenciais. A identidade alélica da geração 20 de um esquema de cruzamento desse tipo é estimada em cerca de 98\%, sendo praticamente idêntica ao genoma compartilhado entre às matrizes da geração anterior (SILVER, 1995). 
A

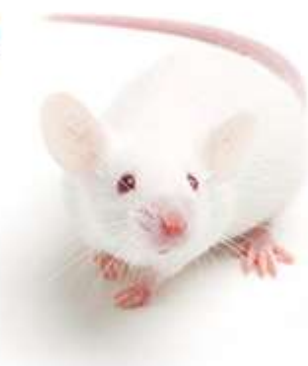

B

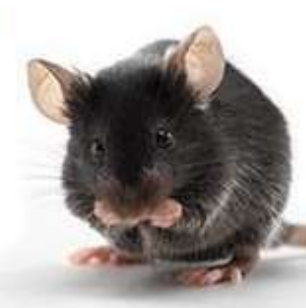

C

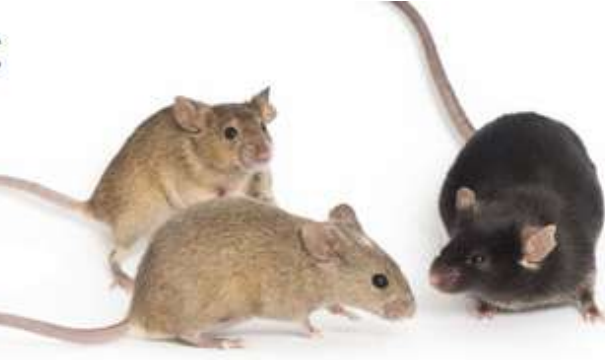

Figura 1.1 Camundongos isogênicos como modelo animal. Linhagens isogênicas, como camundongos BALB/c (A) e C57BL/6 (B) estão entre os mais utilizados. Camundongos geneticamente diversos, como os Diversity Outbred - DO (C) podem ser usados para mapeamento de alta resolução e validação de loci ligados a susceptibilidade a doenças, resistência a drogas e fenótipos de comportamento. Fonte: (A) e (B) - Charles River Laboratories. (C) The Jackson Laboratory.

A utilização de linhagens isogênicas permitiu muitos avanços em estudos fisiológicos, anatômicos, comportamentais e genéticos, devido principalmente a um aumento na reprodutibilidade e no efeito do background genético nos experimentos (JUSTICE; DHILLON, 2016; MANDILLO et al., 2008; RICHTER et al., 2011). Em alguns casos, esse background genético homogêneo não mimetiza a variabilidade genética naturalmente encontrada em populações humanas. Um exemplo é o estudo da resposta a medicamentos na população humana (BOGUE; CHURCHILL; CHESLER, 2015). Atualmente iniciativas de criação de linhagens geneticamente diversas - mas com background conhecido e que ainda mantêm reprodutibilidade alta - como o Collaborative Cross (CC), RIX e Diversity Outcross ou DO (Figura 1.1C) têm sido cada vez mais utilizadas para espelhar a diversidade encontrada naturalmente em populações humanas e são atualmente tendências nesse sentido (BOGUE; CHURCHILL; CHESLER, 2015; YANG et al., 2011). Essas linhagens, criadas a partir de cruzamentos aleatórios de 8 linhagens isogênicas seguida por pelo menos 20 gerações de cruzamentos irmão-irmã possibilitam a inclusão de diversidade genética controlada em experimentos, preservando a possibilidade de 0 uso de painéis de genotipagem para identificação das variações oriundas das linhagens isogênicas utilizadas (BOGUE; CHURCHILL; CHESLER, 2015).

Os camundongos, junto com as moscas Drosophila melanogaster, foram os primeiros organismos mais complexos utilizados para o desenvolvimento de técnicas de manipulação genética (GUÉNET et al., 2015). As tecnologias de manipulação e também de detecção de macromoléculas biológicas tiveram uma importância substancial para o entendimento da biologia humana e na compreensão de 
processos biológicos, formando a base do que hoje entende-se por de genética molecular. As tecnologias de manipulação genética em camundongos podem ser consideradas as mais avançadas entre os modelos de mamíferos e várias dessas tecnologias foram desenvolvidas e aprimoradas em camundongos isogênicos (EPPIG et al., 2015). Estratégias clássicas de mutagênese (MORESCO; LI; BEUTLER, 2013) e transgenia (BOUABE; OKKENHAUG, 2015) foram utilizadas de maneira clássica em camundongos. Abordagens modernas como o silenciamento por RNA de interferência (PREMSRIRUT et al., 2011) e suas variações bem como as técnicas de edição genômica in situ utilizando sistemas de edição genômica CRISPR-Cas9 (STAAHL et al., 2017) também podem ser consideradas tecnologias estabelecidas e frequentemente utilizadas em modelos murinos.

\subsubsection{Genômica de camundongos}

Embora muito utilizado como modelo animal, o sequenciamento completo do genoma de camundongo foi publicado somente em 2002 (MOUSE GENOME CONSORTIUM, 2002). Esse foi um marco muito comemorado, figurando como o segundo genoma de um mamífero a ser completamente sequenciado. Porém, muito antes de 2002, já era conhecido muito a respeito do genoma desses animais devido ao acúmulo de informações de sequenciamentos de genes isolados, experimentos de mutagênese, ensaios de linkage, mapas citogenéticos, painéis de marcadores moleculares, ensaios funcionais diversos e também descrições fenotípicas detalhadas de mutantes (GUÉNET, 2005). Em 1991, todas essas informações começaram a ser compiladas de maneira informatizada por um esforço pioneiro de pesquisadores do The Jackson Laboratory - JAX, que criaram a primeira versão do que ia se tornar a maior e mais completa fonte de informação sobre genômica de camundongos, o Mouse Genome Informatics ${ }^{7}$ - MGI (EPPIG et al., 2015).

Sem dúvidas o sequenciamento do genoma completo do camundongo revelou importantes similaridades com o homem e ainda hoje é utilizado como referência para diversos estudos de genômica funcional, por ser um dos genomas mais estudados e com uma grande quantidade de informações funcionais associadas (BROWN et al., 2009). O genoma de camundongo, em sua primeira

\footnotetext{
${ }^{7} \mathrm{MGI}$ - Mouse Genome Informatics: http://www.informatics.jax.org/
} 
versão, possuía tamanho de 2,5 Gb - cerca de 14\% menor que o genoma humano a uma taxa de erro de sequenciamento estimada de $1 \times 10^{-5}$ (MGS, 2002) - valor que não se alterou muito com a liberação da última versão, atualmente com cerca de 2,6 Gb. Em média, 85\% das regiões codificantes de camundongo podem ser alinhadas com o genoma humano, ao passo que regiões não codificantes são pouco similares - $50 \%$ das sequência ou menos. Cerca de quase $90 \%$ dos genomas de camundongo e humano podem ser agrupados em regiões de considerada sintenia, revelando a conservação da organização estrutural dos cromossomos humanos e murinos em relação a um ancestral comum (GUÉNET, 2005; MGS, 2002).

Curiosamente, o genoma sequenciado em 2002 não corresponde a nenhum camundongo selvagem e sim majoritariamente ao camundongo da linhagem isogênica C57BL/6J (MGS, 2002). Já na época era suposto que o genoma de outras linhagens seria consideravelmente diferente do recente genoma sequenciado e que seria considerado como genoma referência (GUÉNET, 2005). De toda forma, o objetivo do sequenciamento do genoma de camundongo não era a priori investigar a diversidade genética da ampla gama de linhagens isogênicas disponíveis; isso só seria se realizar com o Mouse Genomes Project, a partir de 2011 (KEANE et al., 2011; YALCIN et al., 2011). Inicialmente o projeto sequenciou e analisou 17 linhagens de camundongos. Mais de 120 milhões de SNPs totais foram identificados, sendo que a linhagem C57BL/6NJ, mais próxima ao genoma referência, somou cerca de 1400 SNPs privados e a linhagem PWK/PhJ, mais distante e próxima de camundongos selvagens, somou cerca de 4 milhões de SNPs privados (KEANE et al., 2011). O sequenciamento dessas linhagens em um período tão curto só foi possível devido ao desenvolvimento das tecnologias de sequenciamento NGS, que revolucionaram a genômica como um todo e serão discutidas a seguir.

\subsubsection{Sequenciamento de exomas}

O surgimento das novas tecnologias de sequenciamento, chamadas comumente de sequenciamento de nova geração (NGS, do inglês Next Generation Sequencing), possibilitaram um salto enorme em termos de custo, rapidez e eficiência em genômica. Até 2005, a única abordagem disponível era o sequenciamento tradicional pelo método Sanger - utilizado de maneira integral nos 
primeiros projetos Genoma - efetivo para o sequenciamento de segmentos de DNA pequenos mas com custo muito alto para genomas inteiros (MARDIS, 2013).

A introdução de técnicas de enriquecimento de segmentos de DNA correspondentes ao conjunto de exons aumentou muito a eficiência e os custos de sequenciamento NGS. Um exoma, por definição, é o conjunto de exons dos genes anotados em um genoma referência (WARR et al., 2015). Tipicamente são utilizadas bases de anotação confiáveis, como o CCDS (consensus coding sequence). O alvogenômico a ser sequenciado, no caso de humanos e camundongos, passa de cerca de 3 bilhões de bases para algo em torno de 50 milhões de bases, ou cerca de 1,5\% do genoma total do homem ou do camundongo. Uma síndrome relacionada a um tipo de perda auditiva causada pelo gene dfn82 (WALSH et al., 2010) e uma outra síndrome relacionada a malformações do cérebro (BILGÜVAR et al., 2010) foram as duas primeiras doenças mendelianas humanas descobertas por sequenciamento de exoma, em 2010.

Atualmente, a abordagem mais utilizada para enriquecer amostras de DNA genômico com sequências anotadas como exons é a chamada de captura híbrida em solução (WARR et al., 2015). A captura em solução consiste na hibridização de uma biblioteca de DNA genômico com uma grande variedade de sondas que correspondem à maioria dos exons. As sondas podem ser biotiniladas facilitando a seleção dos fragmentos através de purificação por beads magnéticas (Figura 1.2). Existem vários métodos disponíveis que utilizam a captura em solução em exons, possuindo características singulares se considerarmos a especificidade, cobertura uniforme, maior ou menor número de duplicatas, maior taxa de alinhamento e cobertura de regiões UTR (SEKHAR et al., 2014). Quase todas as abordagens de enriquecimento também estão disponíveis para camundongos, apresentando métricas parecidas em relação às abordagens desenvolvidas para humanos (GAO et al., 2013).

Uma das principais vantagens do sequenciamento de regiões exônicas é a redução dos custos e tempo de análise seguida pela simplificação na interpretação dos resultados em relação ao sequenciamento do genoma completo. A principal desvantagem é a impossibilidade de sequenciamento de todos os exons, devido a restrições de desenho de sondas em determinadas regiões e amplificação diferencial de determinadas regiões por PCR. Além disso, temos a óbvia falta de informação de regiões não exônicas, que podem conter variantes importantes para o 
desenvolvimento de um determinado fenótipo (WARR et al., 2015). Mesmo assim o sequenciamento completo de exomas é considerado uma técnica revolucionária em genômica, principalmente quando aplicada no diagnóstico e descoberta de doenças humanas (KOBOLDT et al., 2013; WARR et al., 2015).

Em camundongos, a primeira utilização do sequenciamento de exomas foi publicada logo em 2011, visando o mapeamento de mutantes induzidos por ENU (FAIRFIELD et al., 2011), baseada nos mesmos princípios utilizados em exomas humanos (Figura 1.2). As abordagens disponíveis para enriquecimento de exons por captura em solução em camundongos são muito similares às metodologias disponíveis para humanos.

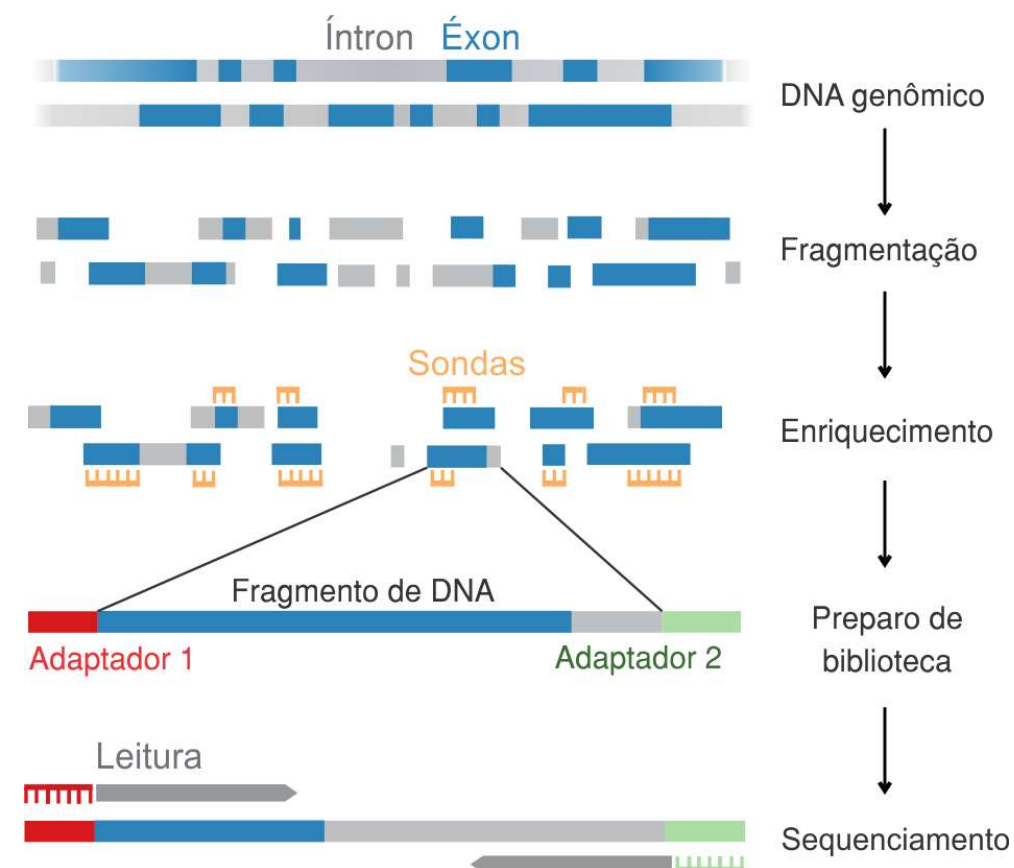

Figura 1.2 Etapas de enriquecimento de regiões exônicas por captura em solução. O DNA genômico é submetido a fragmentação, na maioria das vezes mecânica - por sonicação. Os fragmentos de DNA são então submetidos a hibridização com sondas específicas cujos alvos são regiões exônicas. A captura dos fragmentos hibridizados é feita por beads magnéticas. Os fragmentos de DNA enriquecidos são submetidos ao preparo das bibliotecas, que consiste basicamente na ligação de adaptadores e seleção de tamanho. As bibliotecas são então sequenciadas em plataformas NGS, em modo simples ou em modo paired-end onde são produzidas leituras para ambas as extremidades do fragmento. Adaptado de (DE SOUZA; IENNE, 2018).

O presente estudo, teve como principal objetivo global a aplicação e o desenvolvimento de uma metodologia capaz de identificar variantes em exomas de camundongos tanto em dois grupos distintos: um grupo composto por duas linhagens isogênicas C57BL/6 e BALB/C, mantidas pelo Biotério do ICB e um grupo composto por 7 camundongos mutantes oriundos de um estudo anterior desenvolvido por Massironi e colaboradores (MASSIRONI et al., 2006). Será 
discutido nesse Capítulo o desenvolvimento da abordagem para a execução do sequenciamento do exoma dessas 9 amostras e obtenção das leituras para as análises posteriores de variantes, que serão detalhadas nos Capítulos 2 e 3. 


\section{CAPÍTULO 2 - CARACTERIZAÇÃO DO EXOMA DOS CAMUNDONGOS ISOGÊNICOS C57BL/6-ICBI e BALB/C-ICBI}

\subsection{Introdução}

\subsubsection{Origem das linhagens isogênicas de camundongos}

Camundongos isogênicos são ferramentas básicas em múltiplas áreas da ciência, atuando como modelos tanto para a pesquisa básica quanto em pesquisa aplicada. Considera-se uma linhagem isogênica os indivíduos gerados após a 20a geração de acasalamentos seguidos irmão-irmã. Estima-se que nessa geração, os camundongos irmãos possuam $98,6 \%$ de todos os seus loci em homozigose (BECK et al., 2000; GREEN, 1966). A grande maioria das linhagens isogênicas utilizadas hoje são muito relacionadas em termos de genealogia entre si e foram originadas no início do século XX por pesquisadores do nordeste dos EUA. De fato, evidências sobre a uniformidade do DNA mitocondrial de 16 linhagens isogênicas sugerem que grande parte das linhagens isogênicas foi originada de uma mesma fêmea ancestral há cerca de 150 ou 200 anos atrás (GOIOS et al., 2007).

As linhagens isogênicas de camundongos têm sua história ligada direta ou indiretamente aos trabalhos dos pesquisadores americanos Clarence C. Little, Halsey J. Bagg, Leonell C. Strong, Miss Lathrop e E. Carleton MacDowell no início do século XX (GREEN, 1966). Little tinha como objetivo reduzir o efeito da variabilidade genética no estudo de doenças neoplásicas em camundongos e usou acasalamentos irmão-irmã em sequência para criar uma população que apresentaria a menor variação possível, criando assim os princípios básicos da primeira linhagem isogênica. Os camundongos usados por Little tinham características peculiares de pelagem, chamadas de dilution, brown e nonagouti. Essa linhagem isogênica criada por Little em 1909 ficou conhecida por DBA a partir de 1950 e ainda é muito utilizada em estudos sobre o câncer (GREEN, 1966; GUÉNET et al., 2015).

Em 1913, um outro pesquisador de Nova York, chamado Halsey Bagg, obteve camundongos albinos de um criador no estado de Ohio e os manteve em uma pequena colônia isolada, também com o intuito de estudar o desenvolvimento de neoplasias em camundongos. Seu colega Leonell $C$. Strong utilizou um camundongo da criação de Bagg e um camundongo também albino que Little mantinha em sua criação para o estudo de envelhecimento e câncer. Desse cruzamento a linhagem $A$ começou a ser estabelecida, dando origem às linhagens hoje conhecidas como $A / J$ e A/He. Strong realizou uma série de cruzamentos dos camundongos de Bagg e a 
linhagem DBA, em 1920, dando origem às linhagens $\mathrm{C} 3 \mathrm{H}, \mathrm{CBA}, \mathrm{C}, \mathrm{CHI}$ e Cl2I (GREEN, 1966). George D. Snell, geneticista de Harvard, recebeu também alguns camundongos albinos de Bagg e utilizou a nomenclatura BALB/c para identificar os Bagg alb e a letra "c" para indicar a coloração branca dos mesmos (POTTER; MORRIS, 1985). Em 1980, Snell seria agraciado com o prêmio Nobel em medicina por suas descobertas do complexo $\mathrm{H}-2$ em camundongos, sistema análogo ao complexo de histocompatibilidade MHC em humanos (SNELL, 1980).

Estima-se hoje, que as linhagens isogênicas denominadas de standard, como a C57BL/6J e DBA/2J derivem de contribuições de três subespécies de camundongos diferentes, chamadas de Mus musculus musculus, Mus m. domesticus e Mus m. castaneus (Figura 2.1). Linhagens isogênicas derivadas de uma subespécie única são conhecidas como wild-derived e constituem um pool genético distinto das linhagens standard. São exemplos de linhagens wild-derived: CAST/EiJ, originada a partir de Mus m. castaneus; PWK/PhJ, originada de Mus m. musculus e SPRET/EiJ, originada da subespécie Mus $m$. spretus (BECK et al., 2000).

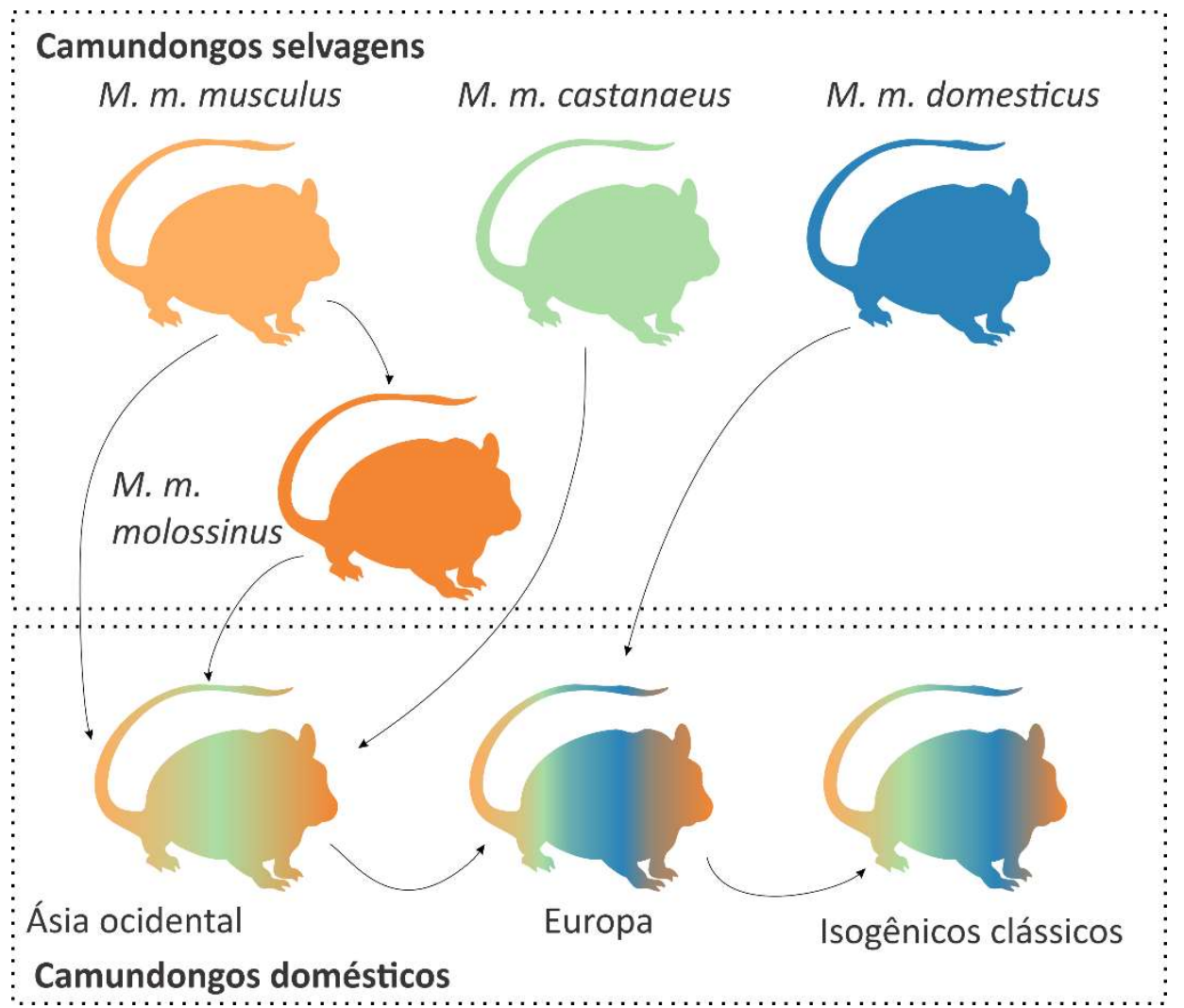

Figura 2.1 Origem dos camundongos isogênicos clássicos. A grande maioria dos camundongos isogênicos de laboratório são derivados de cruzamentos entre três subespécies principais de camundongos (musculus, castanaeus e domesticus) e também com cruzamentos com camundongos japoneses molossinus. Apesar de começarem a ser criados nos EUA, os camundongos foram trazidos da Europa após sua domesticação. Adaptado de (FRAZER et al., 2007). 
Duas linhagens isogênicas standard estão entre as mais utilizadas no mundo: a linhagem C57BL/6, conhecida como black ou C57 e a linhagem BALB/c, conhecida como albino ou BALB. A seguir serão dados mais detalhes sobre a origem e características dessas duas linhagens e as sublinhagens derivadas, principalmente sobre os camundongos mantidos no Biotério do Departamento de Imunologia do Instituto de Ciências Biomédicas da USP, alvos desse estudo.

\subsubsection{Origens e características da linhagem C57BL/6}

Em 1921, nos EUA, Little utilizou camundongos da criação de Miss Lathrop em cruzamentos gerando uma linhagem de pelagem escura, que deu origem às atuais C57BR e C57BL (GREEN, 1966). As sublinhagens 6 e 10 foram separadas antes de 1937, dando origem às atuais C57BL/6 e C57BL/10. Atualmente sabe-se que 6 e 10 se diferenciam pelo menos nos loci H9, lgh2 e $L v$ (MEKADA et al., 2009).

Camundongos C57BL/6 possuem características clássicas que os distinguem de outras sublinhagens C57BL. Eles se reproduzem de maneira rápida (HANSEN, 1973), porém são menos dóceis que outras linhagens (THOMPSON, 1953). Possuem mais atividade locomotora (DAVIS; KING; BABBINI, 1967) e odores (WYSOCKI; WHITNEY; TUCKER, 1977) e preferência aumentada por álcool (FULLER, 1964; LE et al., 1994) e opiáceos, como a morfina (BELKNAP et al., 1993) em relação a outras linhagens. Também possuem uma baixa incidência espontânea de tumores (HOAG, 1963) e são menos responsivos a diversos tipos de infecção por Toxoplasma (MACARIO; STAHL; MILLER, 1980), Leishmania (MONROY-OSTRIA et al., 1994) e Trypanosoma (ROWLAND; LOZYKOWSKI; MCCORMICK, 1992).

Pelo menos nove sublinhagens C57BL/6 foram estabelecidas até 1970 (FESTING, 1996). Duas dessas linhagens tornaram-se as mais famosas e mais utilizadas: a sublinhagem C57BL/6J proveniente do laboratório The Jackson Laboratory - JAX e sublinhagem C57BL/6N, mantida pelo National Institutes of Health - NIH (ALTMAN; KATZ, 1979; BAILEY, 1978). Em 1948, os camundongos C57BL/6 mantidos na JAX - oriundos da criação original de Little nos anos 1930 foram nomeados como C57BL/6J (ALTMAN; KATZ, 1979).

Em 1951, na geração F32 a linhagem foi enviada para o NIH e mantida por décadas em uma colônia isolada, resultando em uma sublinhagem separada, nomeada como C57BL/6N. Animais vivos foram enviados do $\mathrm{NIH}$ para empresas como o Laboratório Charles River em 1974 (C5BL/6NCrl) e Harlan (C57BL/Hsd). Em 
1984, o laboratório $\mathrm{JAX}^{8}$ recebeu embriões congelados da geração F126 e os disponibilizou como C57BL/6NJ. Em 1991 animais da geração F151 também foram enviados do NIH para a Taconic ${ }^{9}$ (C57BL/6NTac). Embora tenham origens diferentes e tenham sido separados por múltiplas gerações, não foram detectadas diferenças em painéis de genotipagem entre as sublinhagens C57BL/6N (ZURITA et al., 2011). A Figura 2.2 detalha as relações entre as sublinhagens C57BL/6 mais utilizadas e fornecidas pelas maiores empresas. Todos os fornecedores, no entanto, aconselham que sejam adquiridos animais da mesma fonte, evitando que variantes genéticas não detectadas possam influenciar os experimentos.

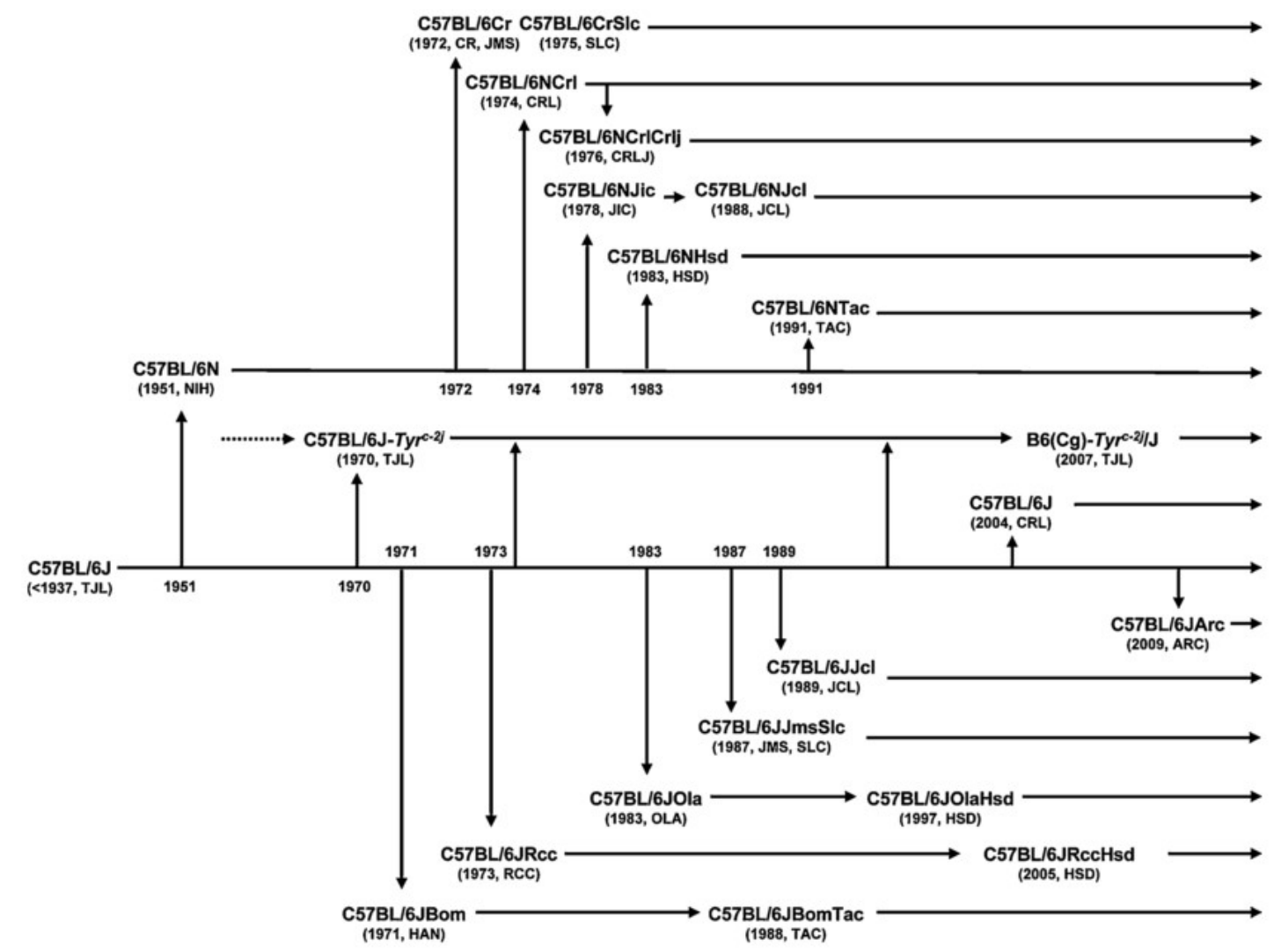

Figura 2.2 Relações entre as sublinhagens mais comuns do camundongo C57BL/6. A genealogia acima, desenhada fora da escala temporal, foi retirada de (ZURITA et al., 2011) com informações de (MEKADA et al., 2009). Fonte: (ZURITA et al., 2011).

Os camundongos gold standard C57BL/6J também podem ser adquiridos de diferentes fontes, mas ainda continuam disponíveis para aquisição direta pela JAX.

\footnotetext{
8 JAX strain C57BL/6J, 27/10/2017: https://www.jax.org/strain/000664

9 Taconic strain C57B/6NTac, 27/10/2017: https://www.taconic.com/mouse-model/black-6-b6ntac
} 
O laboratório Charles River ${ }^{10}$ fornece camundongos para a Ásia e Europa, mas reintroduz frequentemente camundongos da colônia da JAX para evitar efeitos de deriva genética (FONTAINE; DAVIS, 2016). Porém outras instituições mantém camundongos $6 \mathrm{~J}$ em colônias separadas por muito tempo. Os laboratórios ENVIGO"1 oferecem duas sublinhagens $6 \mathrm{~J}$ - C57BL/6OlaHsd e C57BL/6JRccHsd, adquiridas em 1973-1974, que não possuem a mutação nnt encontrada nas outras sublinhagens 6J. Camundongos enviados para o Japão em 1987 constituíram as linhagens C57BL/6JJcl e C57BL/6JJmsSlc não possuem a mutação no gene nnt (MEKADA et al., 2009; SIMON et al., 2013) surgindo que a mutação tenha ocorrido entre 1974 e 1987 (Figura 2.2). Camundongos comercializados na França como C57BL/6JRj desde 1993 possuem diferenças genéticas conhecidas embora possuam a mutação $n n t$ (KERN et al., 2012).

\subsubsection{Diferenças genotípicas e fenotípicas das sublinhagens C57BL/6J e C57BL/6N}

Uma das diferenças genotípicas mais conhecidas foi reportada em 2005 na sublinhagem C57BL/6J, que possui uma deleção nos exons 7-11 do gene que codifica para a nicotinamida nucleotídeo transferase $(n n t)$, intacto nas linhagens C57BL/6N. Essa mutação espontânea que implica na ausência da proteína NNT explica diferenças no controle da secreção de insulina e homeostase de glicose nos camundongos C57BL/6J (TOYE et al., 2005) e também anormalidades na biologia redox em mitocôndrias (RONCHI et al., 2013). A sublinhagem C57BL/6N também é a mais utilizada na produção de células-tronco embrionárias em camundongos, utilizados para nocautes e manipulação gênica (PETTITT et al., 2009). As sublinhagens $6 \mathrm{~N}$ e $6 \mathrm{~J}$ podem ser distinguidas através de vários SNPs em painéis de genotipagem disponíveis, consistindo em uma maneira confiável de controle genético de distinção entre sublinhagens black (MEKADA et al., 2009; ZURITA et al., 2011).

Em 2013 um extenso estudo de comparação entre as sublinhagens 6N e 6J validaram 34 SNPs em regiões codificantes, 2 small indels em regiões codificantes e 43 variantes estruturais, incluindo a mutação nnt (SIMON et al., 2013). Vários genes

${ }^{10}$ Charles River C57BL/6N, 27/10/2017:

http://www.criver.com/files/pdfs/rms/c57bl6/rm_rm_d_c57bl6n_mouse.aspx

${ }^{11}$ ENVIGO, C57BL/6Hsd, 27/10/2017: http://www.envigo.com/products-services/research-modelsservices/models/research-models/mice/inbred/c57bl-6-inbred-mice/ 
contendo essas variantes foram analisados e se destacam os genes vmn2r65 (vomeronasal 2 receptor 65), cyp2a22 (citocromo P450 família 2, subfamília a, polipeptídeo 22), rptor (Raptor - proteína chave na regulação do complexo de sinalização mTORC1), plk1 (importante no ciclo celular), herpud2 (envolvida no processamento de proteínas do retículo endoplasmático), crb1 (mutações provocam degeneração na retina), cyfip2 (função neuronal e polimerização de actina), Ide (envolvida na degradação de insulina) e fgfbp3 (fator de crescimento de fibroblastos) (SIMON et al., 2013).

As principais diferenças clássicas entre os camundongos $6 \mathrm{~N}$ e $6 \mathrm{~J}$ implicam em diferentes respostas para o álcool (KHISTI et al., 2006), susceptibilidade na formação de tumores (DIWAN; BLACKMAN, 1980), pancreatite crônica (ULMASOV et al., 2013), diferenças no desenvolvimento ocular (SIMON et al., 2013) - incluindo catarata e resposta a luz - que podem explicar diferenças na manutenção do ciclo circadiano (BANKS et al., 2015). Outras diferenças como pressão arterial sistólica e habilidade motora (MATSUO et al., 2014) também foram reportadas assim como diferenças na resposta imune ativada por células NK (SIMON et al., 2013). Nem todas as diferenças são explicadas pela falta da proteína Nnt em camundongos 6J apesar do impacto na função mitocondrial (RONCHI et al., 2013), que pode afetar inúmeros processos metabólicos pela regulação de vias redox dependentes de glutationa e tireodoxina/peroxiredoxina (FONTAINE; DAVIS, 2016).

\subsubsection{Origens e características da linhagem $B A L B / C$}

Ao redor de 1930 foi originada a linhagem BALB/c, através do cruzamento de camundongos albinos de Bagg, por MacDowell (GREEN, 1966; GUÉNET et al., 2015). Convenientemente um outro pesquisador, George D. Snell, recebeu os camundongos albinos de Bagg e cunhou a nomenclatura BALB/C (POTTER; MORRIS, 1985), conforme mostrado na Figura 2.3. A linhagem isogênica BALB/c é uma das mais utilizadas no mundo, juntamente com os camundongos C57BL/6 (EPPIG et al., 2015). É particularmente conhecida por fornecer plasmocitomas, tipos de células tumorais que constituem a base para a produção de anticorpos monoclonais (GREENFIELD, 2014).

Três principais sublinhagens BALB/c remontam a 1940 e divergiram devido à heterozigosidade residual presente nas matrizes iniciais e não devido a contaminação com cruzamentos errôneos (POTTER; MORRIS, 1985). Essas três 
sublinhagens são conhecidas como BALB/cHeAn, BALB/cJ e BALB/cRI, diferenciadas por mutações nos locus raf1 - que controla a expressão da alfafetoproteína, qa2 - que controla antígenos de superfície, gdc1 - que codifica para a L-glicerol 3-fosfato desidrogenase no fígado e a sequência repetitiva pr1 (POTTER; MORRIS, 1985).

A colônia da sublinhagem $B A L B / c J$, fornecida atualmente pela $\mathrm{JAX}^{12}$ acumulou 243 gerações em agosto de 2014. Essa linhagem foi originada em 1947 a partir da geração 41 de uma colônia de J. Paul Scott - criada a partir das colônias originais providas por Snell em 1938/1939. A origem dos camundongos fornecidos pela Taconic $^{13}$ é uma colônia em F184 antes de 1988, recebidas pelo NIH provenientes do estoque original de Snell e chamadas de linhagem Andervont. Em 2005 a colônia da Taconic estava em geração F229 muito similar às colônias F221 da JAX.

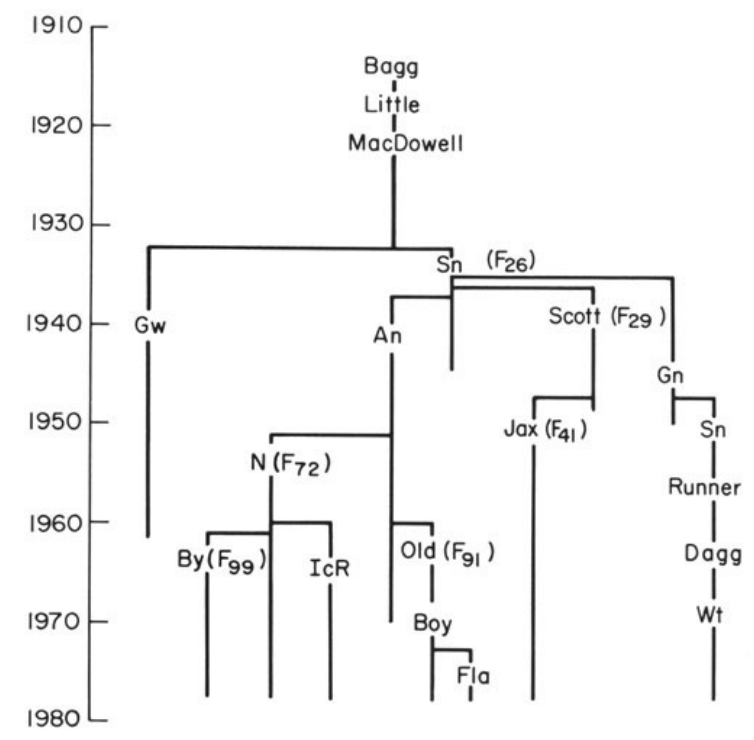

Figura 2.3 Origens da linhagem BALB/c e suas sublinhagens. A genealogia acima foi retirada de (BAILEY, 1978), $\mathrm{Sn}=$ G.D Snell, $\mathrm{Na}=\mathrm{H} . \mathrm{B}$. Andervont, $\mathrm{N}=\mathrm{NIH}, \mathrm{By}=\mathrm{D} . \mathrm{W}$. Bailey, Boy $-\mathrm{E} . \mathrm{A}$. Boyse, $\mathrm{Fla}=\mathrm{L}$. Flaherty, $\mathrm{Gw}=$ J.W. Gowen, $\mathrm{Gn}=\mathrm{E} . \mathrm{L}$. e M.C. Green, JAX = Jackson Laboratory, IcR = Institute for Cancer Research, Wt = W.K. Whitten. Fonte: (BAILEY, 1978).

Camundongos BALB/c são relativamente dóceis, com boa performance reprodutiva e expectativa de vida alta. Também possuem baixa incidência de tumores de mama, mas desenvolvem vários tipos de câncer em idades avançadas - 
incluindo neoplasias reticulares e tumores nos pulmões e rins (HESTON; VLAHAKIS, 1971)- além de constituírem um modelo muito utilizado em pesquisa cardiovascular, por serem resistentes a arteriosclerose induzida por dieta (PAIGEN et al., 1990). Camundongos BALB/c também desenvolvem uma forma atípica de encefalomielite autoimune experimental (EAE) quando imunizados com PLP180-199 (TEUSCHER et al., 1998).

\subsubsection{Breve história das sublinhagens C57BL/6-ICBI e BALB/C-ICBI}

O Instituto de Ciências Biomédicas, através do biotério de experimentação do Departamento de Imunologia, fornece diversas linhagens isogênicas e co-isogênicas - camundongos transgênicos ou mutantes. A linhagem C57BL/6 é atualmente a linhagem mais utilizada pelos pesquisadores seguida da linhagem BALB/c (MASSIRONI, comunicação pessoal).

A colônia C57BL/6 do ICB foi originada de matrizes do CEMIB/UNICAMP, denominada atualmente de C57BL/6JUnib ${ }^{14}$ (RONCHI et al., 2013), oriundas originalmente da Universidade de Medicina Veterinária em Hannover-Alemanha (Zentralinstitut für Versuchstierzucht, Hannover), em meados de 1980 (MASSIRONI, comunicação pessoal), presumidamente de uma colônia C57BL/6N. A colônia $B A L B / C$ do ICB foi originada com matrizes originadas da sublinhagem BALB/CJ, provenientes do Instituto Pasteur (França), no início dos anos 90 (Figura 2.4), como doação do Prof. Jean Louis Guénet. Essa colônia também é mantida há pelo menos 25 anos e também pode ser considerada uma sublinhagem originada a partir da sublinhagem BALB/cJ (MASSIRONI, comunicação pessoal).

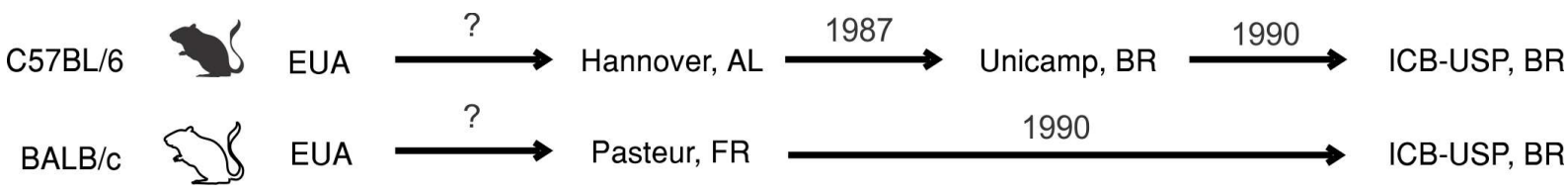

Figura 2.4 Origens das sublinhagem C57BL/6ICBI e BALB/cICBI. O camundongo C57BL/6ICBI foi trazido de Hannover, Alemanha, em 1987 para o CEMIB-UNICAMP, em Campinas. Alguns anos mais tarde foi introduzido no ICB, formando a colônia atual do Biotério. Não se sabe a origem da colônia de Hannover, mas presume-se que foi originada do NIH (C57BL/6N) nos EUA. Os camundongos $\mathrm{BALB} / \mathrm{clB}$ foram trazidos no início da década de 90 diretamente do Instituto Pasteur para o ICB-USP.

${ }^{14}$ CEMIB, UNICAMP: www.cemib.unicamp.br 
Desde então, as linhagens são mantidas através de sucessivos cruzamentos irmão-irmã na colônia sendo tanto a linhagem C57BL/6 quanto a linhagem BALB/C mantidas em populações isoladas. Considerando a duração de uma geração como 12 semanas, os camundongos do ICB estariam em sua $108^{\mathrm{a}}$ geração desde 1990. Portanto, segundo os critérios clássicos, as colônias são consideradas sublinhagens e por esse motivo, as sublinhagens disponíveis no ICB-USP serão identificadas como C57BL/6ICBI e BALB/CICBI, segundo as recomendações de nomenclatura sugeridas pela $J A X^{15}$.

\subsubsection{Sublinhagens e seu impacto na reprodutibilidade e interpretação de experimentos}

Ao contrário do senso comum, camundongos isogênicos não são completamente idênticos geneticamente entre si e novas variações podem ser fixadas devido à inúmeros fatores de seleção e fixação de alelos (CASELLAS, 2011), originando sublinhagens que podem se comportar de maneira muito heterogênea em termos de fenótipo. Um estudo de 2008 (CASELLAS; MEDRANO, 2008) estimou em $\sim 4,5 \%$ do total da variabilidade fenotípica em camundongos C57BL/6J foi devido a novas mutações que acumularam na colônia em poucas gerações, provavelmente por deriva genética. Quando essas variações são fixadas em uma determinada colônia - isolada geograficamente e fundada por poucos animais oriundos de uma linhagem parental - surge o que chamamos de sublinhagem, cujos membros podem diferir consideravelmente em termos de background genético com sua linhagem parental (COLETTI et al., 2013; NICHOLSON et al., 2010).

Sublinhagens podem surgir devido a vários fatores, como heterozigosidade residual (BAILEY, 1978); mutações espontâneas fixadas por deriva genética (CASELLAS, 2011; WOTJAK, 2003); contaminação acidental com outras linhagens (NAGGERT et al., 1995; WOTJAK, 2003); um novo status em uma colônia - como certificações livre de patógeno, por exemplo, e finalmente a própria separação de uma subcolônia da sua colônia parental por 20 ou mais gerações. Todas essas razões são suficientes para analisar cuidadosamente respostas de um modelo 
murino de uma maneira reprodutível e interpretá-las da melhor forma possível (JUSTICE; DHILLON, 2016; MANDILLO et al., 2008).

Infelizmente, todo o grau de diversidade genética entre sublinhagens e até mesmo linhagens não é muito bem caracterizado. Apesar do conhecimento crescente sobre as variações fenotípicas entre linhagens e toda a complexidade da base genética no fenótipo (SHAO et al., 2008), das variantes mendelianas até a complexidade infinitesimal da maioria dos traços fenotípicos quantitativos (FLINT; MACKAY, 2009), não conhecemos a base molecular da maioria dos fenótipos que são influenciados diretamente pelo background genético. Os estudos mantidos pelo Mouse Genomes Project vêm colaborando muito com o conhecimento sobre a variação genética em camundongos e seu impacto no fenótipo (KEANE et al., 2011), potencializados pelo sequenciamento do genoma de várias linhagens isogênicas (DORAN et al., 2016; YALCIN et al., 2012). No entanto, muitos estudos apontam para diferenças fenotípicas significativas entre sublinhagens, como por exemplo diferenças comportamentais (STIEDL et al., 1999), rejeição de tecidos em sublinhagens 129 (SIMPSON et al., 1997) e susceptibilidade diferencial a tumores em C3H (GLANT et al., 2001). O exemplo mais marcante das diferenças entre sublinhagens permanece com os camundongos C57BL/6J e C57BL/6N, usados durante muito tempo como sendo de certa forma equivalentes. Esses camundongos black apresentam respostas completamente diferentes a diversos experimentos como: resposta ao medo (STIEDL et al., 1999), anestésicos e função cardíaca (ROTH et al., 2002) e limiares de eletro convulsão (YANG et al., 2003).

Considerando a era pós-genômica em que estamos inseridos, é muito importante entender o background genético dos modelos utilizados, o que pode significar um salto qualitativo enorme para a interpretação e reprodutibilidade dos dados (COLETTI et al., 2013; SITTIG et al., 2014). Caracterizar geneticamente sublinhagens de camundongos deve ser vista como uma realidade, visto os custos cada vez menores de sequenciamento (YALCIN et al., 2012).

A caracterização genética das sublinhagens isogênicas mantidas no ICB é, portanto, essencial para a avaliação comparativas dos animais no seu contexto genético e possibilita o rastreio de mutações espontâneas fixadas na população, servindo de referência para os estudos desenvolvidos com esses animais por pesquisadores do Instituto e de outras instituições pelo Brasil. Esse estudo pode ser considerado um esforço pioneiro no sentido de aprofundar o nível de informação 
levada ao pesquisador em termos de controle genético e manutenção de colônias, de forma a facilitar a detecção de mutações espontâneas e contaminações, estimulando a enorme importância de estudos frequentes e sistematizados nesse sentido. 


\section{CAPÍTULO 3 - SEQUENCIAMENTO DOS CAMUNDONGOS MUTANTES POR MUTAGÊNESE INDUZIDA POR ENU.}

\subsection{Introdução}

3.1.1 Genética direta ou forward genetics

Camundongos mutantes constituem uma importante ferramenta na identificação de fatores genéticos responsáveis diretamente por fenótipos complexos. A geração de camundongos nocautes ou knockouts (Figura 3.1) tem sido uma abordagem frequente para a inativação de genes seguida pela caracterização funcional dos mesmos (ANTONARAKIS; BECKMANN, 2006; GONDO, 2010). Porém, doenças humanas em sua maioria são causadas por mutações que alteram funcionalmente os produtos gênicos ou sua regulação ao invés de simplesmente desativá-los (COOPER et al., 2011). Portanto, o estudo de modelos animais obtidos por mutagênese aleatória ou dirigida (CRISPR-Cas9) (Figura 3.1) pode contribuir tanto com a elucidação da função dos genes quanto com a caracterização de doenças genéticas humanas (OLIVER; DAVIES, 2012).

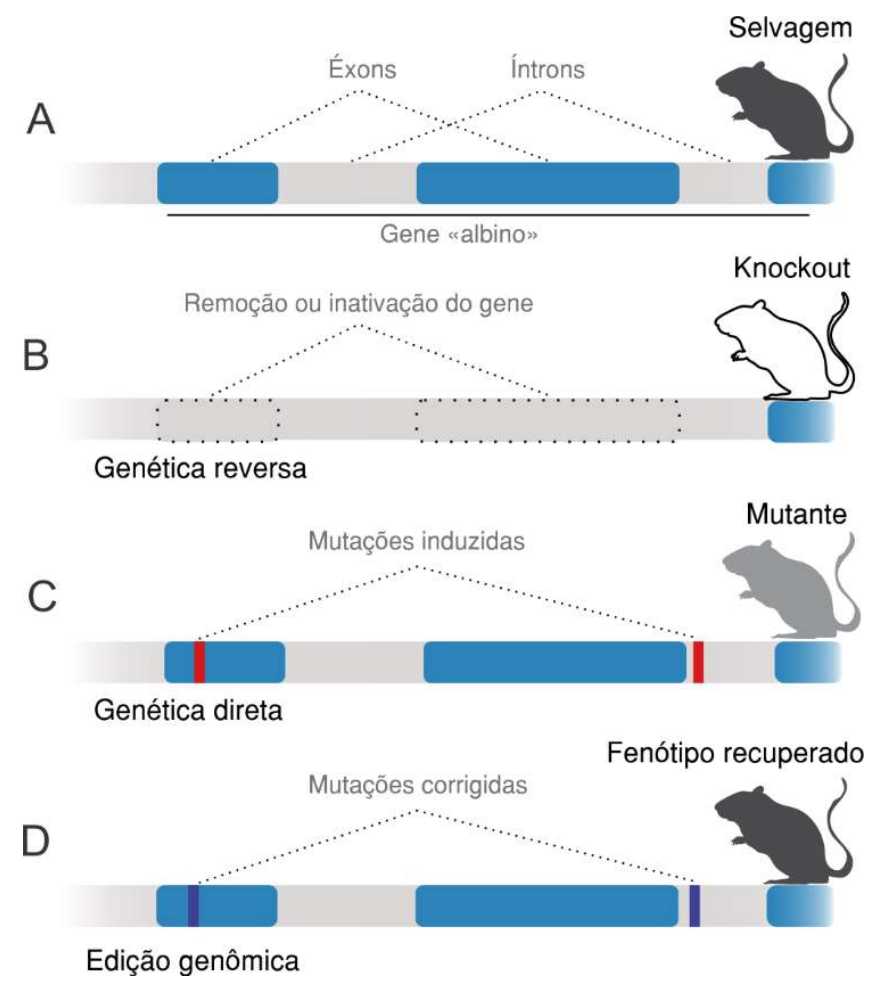

Figura 3.1 Abordagens para a compreensão da função dos genes usando modelos. A função de um hipotético gene "albino", envolvido na cor da pelagem em camundongos (A), pode ser investigada a partir da deleção ou inativação do gene (um knockout) e observação direta do fenótipo (B). Mutantes induzidos podem revelar detalhes mais finos sobre a função do gene (C) por genética direta, já que são observadas mutações pontuais que mimetizam alelos naturais. Recentemente, o desenvolvimento de ferramentas de edição genômica, como CRISPR-Cas, possibilitam a correção direcionada de mutações pontuais, restaurando o fenótipo selvagem. 
A indução de mutações aleatórias através do uso de agentes mutagênicos é uma forma de acelerar e aumentar a diversidade de fenótipos em contrapartida à observação de fenótipos gerados a partir de mutações espontâneas (BULL et al., 2013). Vários agentes mutagênicos podem ser usados em varreduras de genética direta, desde agentes mutagênicos físicos como a radiação gama como agentes químicos como o etilmetanosulfonato (EMS) e N-etil-N-nitrosuréia (ENU) ou agentes mutagênicos endógenos como elementos de transposição (FARRELL et al., 2014).

A genética direta possui vantagens em relação à genética reversa, principalmente por ser guiada por variações fenotípicas e de certa forma por mimetizar variações pontuais que são mais prováveis de serem encontradas na natureza, como em síndromes mendelianas clássicas (BULL et al., 2013). É um tipo de abordagem que permite a seleção de fenótipos interessantes sem que haja nenhuma hipótese relacionada à base genética envolvida. Além disso, é um dos melhores métodos para a determinação da função de um gene, ao observar os fenótipos de organismos individuais que possuem uma mutação no próprio gene (MORESCO; LI; BEUTLER, 2013).

Uma das vantagens do uso de varreduras de genética direta é a liberdade em relação ao conhecimento prévio da sequência de DNA mutada. Essa vantagem se torna uma desvantagem devido à dificuldade dos procedimentos de localização ou mapeamento da mutação (BULL et al., 2013). Durante muito tempo essas abordagens não triviais consistiram em utilizar marcadores moleculares, como microssatélites e RFLPs, para mapear as mutações no genoma (JUSTICE et al., 1999). Através do uso de microssatélites, a mutação era localizada em um mapa de recombinação e somente a região-alvo que segregava com o fenótipo era identificada através de sequenciamento (HERRON et al., 2002). Esse tipo de estudo é chamado de triagem de mutagênese e pode ser usado para caracterizar genes específicos que afetam uma determinada função ou fenótipo complexo (CORDES, 2005; JUSTICE et al., 1999). O sequenciamento completo do genoma de camundongo facilitou muito a procura e seleção de candidatos, e ficou ainda mais rápido e menos custoso com o advento do uso de tecnologias de sequenciamento de nova geração (NGS) na procura pelos candidatos (ARNOLD et al., 2011; BOLES et al., 2009; BULL et al., 2013; FAIRFIELD et al., 2011). 


\subsubsection{Mutagênese por ENU e varredura de mutantes}

$\mathrm{O}$ agente mutagênico $\mathrm{N}$-etil-N-nitrosouréia ou ENU (Figura 3.2) tem sido usado em larga escala desde a década de 1990 para o estabelecimento de modelos de doenças humanas em camundongos (GUÉNET, 2005) e peixe-zebra (PATTON; ZON, 2001). O ENU pode introduzir mutações pontuais randômicas em virtualmente qualquer região do genoma de células tronco de espermatogônias a uma frequência de $\sim 150 \times 10^{-5}$ por locus (SHIBUYA; MORIMOTO, 1993). A mutagênese ocorre principalmente devido a trocas de uma única base pela alquilação direta dos ácidos nucleicos. O grupo etil do ENU pode ser transferido a um oxigênio preferencialmente em O4-timina, O2-timina ou O2-citosina ou a um nitrogênio nas bases do DNA (KOELSCH; KINDLER-RÖHRBORN, 2009) (Figura 3.2). Durante a replicação do DNA, essas bases contendo aduto etil podem causar erro no pareamento das bases, introduzindo principalmente mutações pontuais (substituição de base), mesmo que eventualmente possam ocorrer também pequenas deleções e inserções (TAKAHASI; SAKURABA; GONDO, 2007). As mutações mais comumente observadas são transversões TA:AT ou transições TA:CG (JUSTICE et al., 1999; SHIBUYA; MORIMOTO, 1993).

A

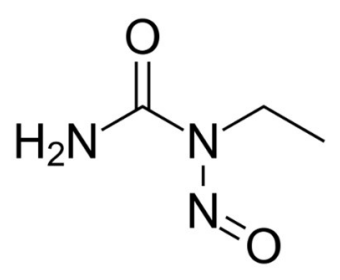

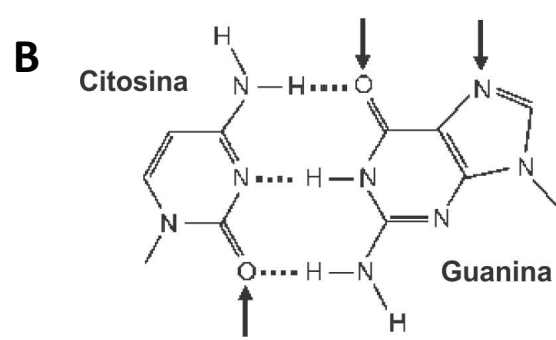

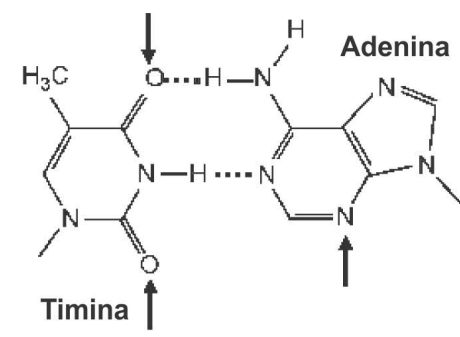

Figura 3.2 $\mathrm{O}$ agente mutagênico $\mathrm{N}$-etil-N-nitrosouréia (ENU). Estrutura química do ENU (fórmula química $\mathrm{C}_{3} \mathrm{H}_{7} \mathrm{~N}_{3} \mathrm{O}_{2}$ ) (A) e átomos alvos nas bases do DNA indicados pelas setas (adaptado de KOELSCH; KINDLER-RÖHRBORN, 2009).

Várias estratégias foram desenvolvidas para a utilização de ENU em genética direta, basicamente envolvendo o tratamento de espermatogônias com doses controladas de ENU causando mutações pontuais em células germinativas. Os machos tratados com ENU passam por um período de descanso e são então cruzados com fêmeas não tratadas por uma ou duas gerações originando proles mutantes (Figura 3.3). Alterações fenotípicas visíveis, de herança dominante ou recessiva, são recuperadas para estabelecimento de testes para a seleção e 
caracterização dos candidatos para a mutação causal do fenótipo observado (MASSIRONI et al., 2006).

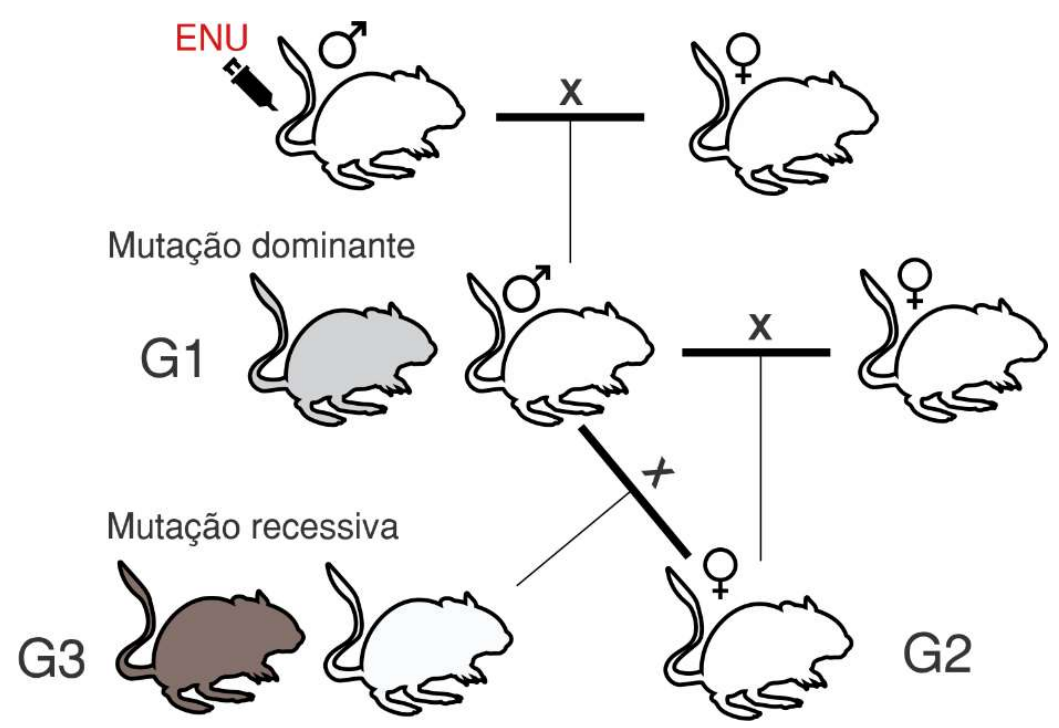

Figura 3.3 Estratégia de varredura de genética direta de mutagênese por ENU. Camundongos $B A L B / c$ tratados com ENU são acasalados com várias fêmeas BALB/c e sua progênie (G1) é observada para deteç̧ão de fenótipos de herança dominante. Os machos $\mathrm{G} 1$ são então acasalados com fêmeas BALB/c produzindo a geração $G 2$. O acasalamento de fêmeas $\mathrm{G} 2$ com seu pai $\mathrm{G} 1$ dá origem a progênie G3, cujos fenótipos mutantes são de herança recessiva. Adaptado de (MASSIRONI et al., 2006).

A natureza aleatória desse tipo de mutagênese pode gerar fenótipos semelhantes a doenças humanas e acentuar determinadas vias de sinalização (SIMON et al., 2015). Isso significa que a função de novos genes pode ser descoberta sem que nenhuma anotação esteja disponível, já que nenhum gene em particular é um alvo específico da técnica.

Várias linhagens podem ser utilizadas, mas a linhagem mais utilizada para varreduras de mutagênese por ENU é a C57BL6/J, por causa principalmente da fertilidade elevada mesmo após o tratamento por altas doses de ENU (JUSTICE et al., 1999). Empregar a mesma linhagem em uma varredura significa reduzir a variação no background genético, facilitando a detecção de fenótipos variantes. Empregar mais de uma linhagem nas varreduras dificulta a distinção entre um provável fenótipo gerado pela mutagênese e entre fenótipos gerados pela mistura entre linhagens diferentes (GONDO, 2010).

A estratégia de indução de mutações pontuais por ENU aliada a uma seleção fenotípica consistente constitui uma ferramenta poderosa para identificação de mutações responsáveis por fenótipos complexos (ARNOLD et al., 2012). Considerando os estudos que correlacionaram as mutações identificadas aos 
fenótipos observados, cerca de $75 \%$ dos fenótipos observados por mutagênese por ENU foram causadas por SNVs (single nucleotide variants) em exons (JUSTICE et al., 1999). Aproximadamente $63 \%$ destas são mutações do tipo missense, $26 \%$ causaram splicing anormal, $10 \%$ são mutações nonsense e aproximadamente $1 \%$ causaram mutações que converte um códon de parada em códon que codifica um aminoácido (NOVEROSKE; WEBER; JUSTICE, 2000).

\subsubsection{Mapeamento das mutações}

Um dos maiores gargalos para o estudo de mutantes induzidos por ENU é a identificação da mutação pelo mapeamento genético fino utilizando marcadores polimórficos seguido pelo sequenciamento (pelo método Sanger) de exon por exon de um ou mais genes na região mapeada. De maneira clássica, a localização - ou mapeamento - de loci afetados por uma mutação é baseada na detecção do desequilíbrio de ligação depois de uma varredura genômica com marcadores moleculares. Esse mapeamento requer uma série de cruzamentos, onde o fenótipo deverá segregar com o maior número possível de polimorfismos detectáveis (BEIER; HERRON, 2004). Isso significa, por definição utilizar cruzamentos linhagens diferentes do background utilizado nos mutantes. A escolha de linhagens isogênicas distantes da linhagem isogênica onde a mutação foi induzida melhora a distribuição e densidade dos polimorfismos de todos os tipos ao longo do genoma (BECK et al., 2000).

No caso de fenótipos cuja herança é recessiva, os cruzamentos para mapeamento das mutações consistem basicamente em cruzamentos entre mutantes homozigotos com a linhagem distante. A progênie é então cruzada com mutantes heterozigotos, sendo realizados intercrossing ou bakcrossing com mutantes da linhagem de origem da mutação heterozigotos, dando origem a geração F2. Todos os camundongos que apresentarem fenótipo em F2 são considerados para o mapeamento com marcadores moleculares (MASSIRONI et al., 2006). Esse mapeamento consiste no uso de mais de 50 marcadores moleculares microssatélites polimórficos entre as duas linhagens utilizadas nos cruzamentos de mapeamento. Pelo menos 50 amostras de DNA da geração F2 que apresentam fenótipo mutante são utilizados para a primeira varredura, que visa a localização cromossomal das mutações. Uma vez que é encontrado o desequilíbrio de ligação mais marcadores do mesmo cromossomo são utilizados para confirmar e refinar a localizar a mutação - procedimento que é conhecido 
como mapeamento de alta-resolução (MASSIRONI et al., 2006). Após o mapeamento fino é utilizada a clonagem posicional de vários segmentos de DNAalvo para sequenciamento Sanger. Dependendo do tamanho da região mapeada, que pode variar de poucas kilobases até o nível de megabases - são utilizados vários pares de oligonucleotídeos visando amplificar subdivisões da região-alvo em produtos de amplificação de até $1000 \mathrm{kbp}$, que são sequenciados individualmente (KILE; HILTON, 2005).

Além do mapeamento tradicional com microssatélites, painéis de hibridização (microarranjos de DNA) têm sido utilizados para varreduras em conjuntos de SNPs de exomas, apesar de serem restritos (MORAN et al., 2006; SUN et al., 2012). Esse processo teve muito sucesso no passado mas é lento e requer trabalho intensivo e também envolve assumir correlações diretas entre a causa genética e o fenótipo (MORESCO; LI; BEUTLER, 2013).

Com o uso de técnicas modernas de sequenciamento esse gargalo diminuiu consideravelmente, de forma a aumentar a chance, a rapidez e a confiabilidade na identificação das mutações candidatas. Considerando que aproximadamente 40$75 \%$ das mutações induzidas por ENU e causadoras de fenótipo foram identificadas em exons, alguns grupos de pesquisa vêm identificando mutações induzidas por ENU utilizando análises por sequenciamento do exoma (WES, do inglês, Whole Exome Sequencing) (ENDERS et al., 2012; FAIRFIELD et al., 2011, 2015; SUN et al., 2012). Ao considerar o sequenciamento completo do genoma (WGS) cerca de $90 \mathrm{~Gb}$ de dados de sequenciamento são necessários para alcançar cerca de 30X de cobertura média, enquanto apenas $3 \mathrm{~Gb}$ são necessários para alcançar quase $75 \mathrm{X}$, quase o dobro da cobertura média, em se tratando de exomas.

As tecnologias de NGS e também os algoritmos de identificação de SNVs possuem uma taxa de erro e de falsos-positivos elevada em comparação com o sequenciamento Sanger. Além disso, exons não anotados, promotores e enhancers não são consideradas em WES, apesar do reconhecimento cada vez maior dessas regiões em doenças e manifestações fenotípicas (ZHANG; LUPSKI, 2015). Variantes estruturais como inserções, deleções e translocações também não são identificadas com precisão em WES (WARR et al., 2015), embora também possam ser originadas por processos mutagênicos induzidos ou espontâneos (MORESCO; LI; BEUTLER, 2013). 
3.1.4 Características gerais dos mutantes BALB/c selecionados induzidos por ENU

A estratégia de mutagênese por ENU foi o objetivo do projeto "O CAMUNDONGO COMO ORGANISMO MODELO - MAPEAMENTO DE MUTAÇÕES INDUZIDAS POR ETIL-NITROSOURÉIA" apoiado pela FAPESP (Projetos 00/069635 e 03/04531-9) coordenado pela Dra. Silvia Massironi. O projeto deu origem a 11 camundongos mutantes com fenótipos diversos (MASSIRONI et al., 2006), gerados pelo esquema de varredura (Figura 3.3) em camundongos BALB/c e mantidos em background BALB/c. O mapeamento dessas mutações foi iniciado pelos métodos tradicionais utilizando-se microssatélites (RHODES et al., 1998) por mapeamento meiótico convencional e foram identificados, no mínimo, os cromossomos onde as mutações se localizavam. Em alguns casos, foi possível realizar a identificação dos genes candidatos posicionais determinados por sequenciamento pelo método de Sanger. Esse método foi utilizado, por exemplo, para o sequenciamento da mutação Anêmico, cujo gene causal codifica a hemoglobina, que tem poucos exons. Para outras mutações os tamanhos do genoma contendo genes candidatos são muito maiores, o que dificulta e encarece essa estratégia (JUSTICE et al., 1999).

A Tabela 3.1 apresenta dados de 7 mutantes, cujas mutações não foram identificadas pelos métodos convencionais, e seus controles, estão sendo estudados neste projeto. Observa-se que os nomes dos mutantes se referem ao principal fenótipo observado, uma vez que o gene mutado ainda não era conhecido.

Tabela 3.1 Camundongos mutantes e linhagens selvagens selecionados para o projeto.

\begin{tabular}{|c|c|c|c|c|c|c|}
\hline Mutação & $\begin{array}{l}\text { Tipo de } \\
\text { Herança }\end{array}$ & $\begin{array}{l}\text { Backgrou } \\
\text { nd }\end{array}$ & $\begin{array}{l}\text { Principal fenótipo } \\
\text { observado }\end{array}$ & Cromossomo $^{a}$ & $\begin{array}{l}\text { Posição } \\
\text { (cM) }{ }^{a}\end{array}$ & $\begin{array}{c}\text { Grupo } \\
\text { Colaborador }\end{array}$ \\
\hline ataxico 1 & recessivo & $\mathrm{BALB} / \mathrm{c}$ & Roda em círculos & 10 & $25-40$ & ICB/UNIFESP \\
\hline bate palmas & recessivo & $\mathrm{BALB} / \mathrm{c}$ & $\begin{array}{l}\text { Não sustenta as pernas } \\
\text { traseira na natação }\end{array}$ & 15 & $19-37$ & ICB/FMVZ \\
\hline careca & recessivo & $\mathrm{BALB} / \mathrm{c}$ & Pelagem rala por toda a vida & 7 & $70-78$ & ICB/FMVZ/UFMG \\
\hline cruza pernas & recessivo & $\mathrm{BALB} / \mathrm{c}$ & $\begin{array}{l}\text { Cruza pernas traseira quando } \\
\text { segurado pela cauda }\end{array}$ & 11 & $27-58$ & ICB/FMVZ \\
\hline equilíbrio & recessivo & $\mathrm{BALB} / \mathrm{c}$ & $\begin{array}{c}\text { Não se equilibra no rota rod. } \\
\text { Desorganização da camada } \\
\text { de Purkinje }\end{array}$ & 17 & $1-10$ & $\begin{array}{l}\text { ICB/UNIFESP e } \\
\text { FMVZ }\end{array}$ \\
\hline fraqueza & recessivo & $\mathrm{BALB} / \mathrm{c}$ & $\begin{array}{l}\text { Perda progressiva da } \\
\text { coordenação motora }\end{array}$ & 1 & $11-81$ & ICB/UFMG \\
\hline Sacudidor & dominante & $\mathrm{BALB} / \mathrm{c}$ & $\begin{array}{l}\text { Sacode a cabeça } \\
\text { continuamente }\end{array}$ & 15 & $32-57$ & ICB/UFMG \\
\hline C57BL/6 & - & - & - & - & - & $\begin{array}{l}\text { Biotério Imunologia } \\
\text { ICB }\end{array}$ \\
\hline $\mathrm{BALB} / \mathrm{c}$ & - & - & - & - & - & $\begin{array}{l}\text { Biotério Imunologia } \\
\text { ICB }\end{array}$ \\
\hline
\end{tabular}




\subsubsection{Resumo das características individuais dos mutantes}

Atáxico-1: Os camundongos mutantes Atáxico-1 (atxrec1) possuem como traço fenotípico principal o movimento estereotipado de rodar em círculos. Esse fenótipo possui herança mendeliana recessiva, cuja mutação foi mapeada por microssatélites no cromossomo 10 entre 25 e 40 cM. Além de movimentos estereotipados, os camundongos atxrec1 apresentam tremores, disbasia, movimento involuntário da cabeça, ausência de respostas de reflexo variadas, discreto atraso na abertura das pálpebras e infertilidade em machos da ordem de $95 \%$. Esses animais são estudados pelo grupo da Profa. Marimélia Porcionatto, do Departamento de Bioquímica, da Escola Paulista de Medicina da UNIFESP (Massironi; Mori, comunicação pessoal).

Bate palmas: O mutante batepalmas (bapa) (Figura 3.4B) é mantido em background BALB/C e apresenta alterações fenotípicas de herança recessiva marcantes como: movimento repetitivo das patas dianteiras quando suspenso pela cauda (MASSIRONI et al., 2006); incapacidade de nadar quando colocado em água e deficiência em testes comportamentais de orientação espacial (Massironi; Mori, comunicação pessoal). Análises comportamentais recentes indicam uma possível deficiência motora, com menores níveis de ansiedade sem perda de memória (OLIVEIRA, 2017). Atualmente o camundongo bapa é modelo de estudo do grupo da Profa. Cláudia Mori, do Departamento de Patologia da Faculdade de Medicina Veterinária e Zootecnia da USP.

Careca: A mutação careca (carc) induz anomalias no pelo da primeira pelagem - que é esparsa durante toda a vida do camundongo, especialmente em redor dos olhos, membros e parte ventral. Logo após o desmame os camundongos perdem toda sua pelagem, depois disso a pelagem reaparece sempre com falhas. Análises histológicas mostram um aumento da camada de pele devido ao alto número de folículos em fase anágena (MASSIRONI et al., 2006). A mutação carc foi mapeada no cromossomo 7, provavelmente entre 70 e $78 \mathrm{cM}$ - porém preferimos considerar que a mutação estaria restrita a todo o cromossomo 7 . Esse mutante está sendo estudado pelo grupo da Profa. Ana Lúcia Godard do Depto. de Biologia Geral, do Instituto de Ciências Biológicas, da UFMG.

Cruza pernas: Camundongos cruza pernas (crup) (Figura 3.4D) foram identificados pelo fenótipo característico do cruzamento das patas traseiras entre si 
quando suspensos pela cauda (MASSIRONI et al., 2006). Esse fenótipo é acentuado com o envelhecimento, sendo que após seis a oito meses de idade os camundongos se enrolam, juntando as patas traseiras e dianteiras. É uma mutação recessiva e foi localizada, através do mapeamento por microssatélites no cromossomo 11 entre 27 e 58 cM (MASSIRONI, comunicação pessoal). É estudado pelo grupo da Profa. Cláudia Mori, da FMVZ-USP.

Equilíbrio: A mutação eqlb (Figura 3.4C) é caracterizada pelo fenótipo de coordenação motora anormal, verificado pela incapacidade dos camundongos eqlb se manterem no aparato rota-rod, sugerindo algum defeito no controle do equilíbrio. Os camundongos eqlb apresentam proliferação de precursores neuronais no cerebelo durante o desenvolvimento pós-natal acompanhada da desorganização da camada de Purkinje (Mazzonetto, dados não publicados). Esse mutante é estudado pelo grupo da Profa. Marimélia Porcionatto, da UNIFESP e pelo grupo da Profa. Cláudia Mori, da FMVZ-USP.

Fraqueza: $O$ mutante fraqueza (frqz) (Figura 3.4A) apresenta perda progressiva da coordenação motora, que fica evidente à partir da segunda semana de vida e raramente sobrevivem à quarta semana de vida (Massironi, comunicação pessoal). Cortes histológicos dos músculos mostraram núcleos corados, indicando processo inflamatório e morte celular. Nervos e gânglios intra-espinais apresentam degeneração acompanhados por neurônios medulares anucleados, indicando também morte celular (SILVA SILVA; GODARD, 2012). A mutação foi mapeada previamente na região entre 11 e $81 \mathrm{cM}$ do cromossomo 1 (MASSIRONI et al., 2006) e esse mutante está sendo estudado pelo grupo da Profa. Ana Lúcia Godard da UFMG.

Sacudidor: Única mutação dominante do grupo estudado, camundongos Sacc apresentam contínuo movimento de balanço da cabeça mas sem apresentar o comportamento de andar em círculos. A intensidade do movimento da cabeça aumenta quando o animal é perturbado. Não são surdos - quando estimulados por um pulso agudo sonoro geram o reflexo de Preyer (MASSIRONI et al., 2006). A mutação foi mapeada por microssatélites no cromossomo 15 entre as regiões 32 e 57 cM. Também estão sendo estudados pelo grupo da Profa. Ana Lúcia Godard da UFMG. 


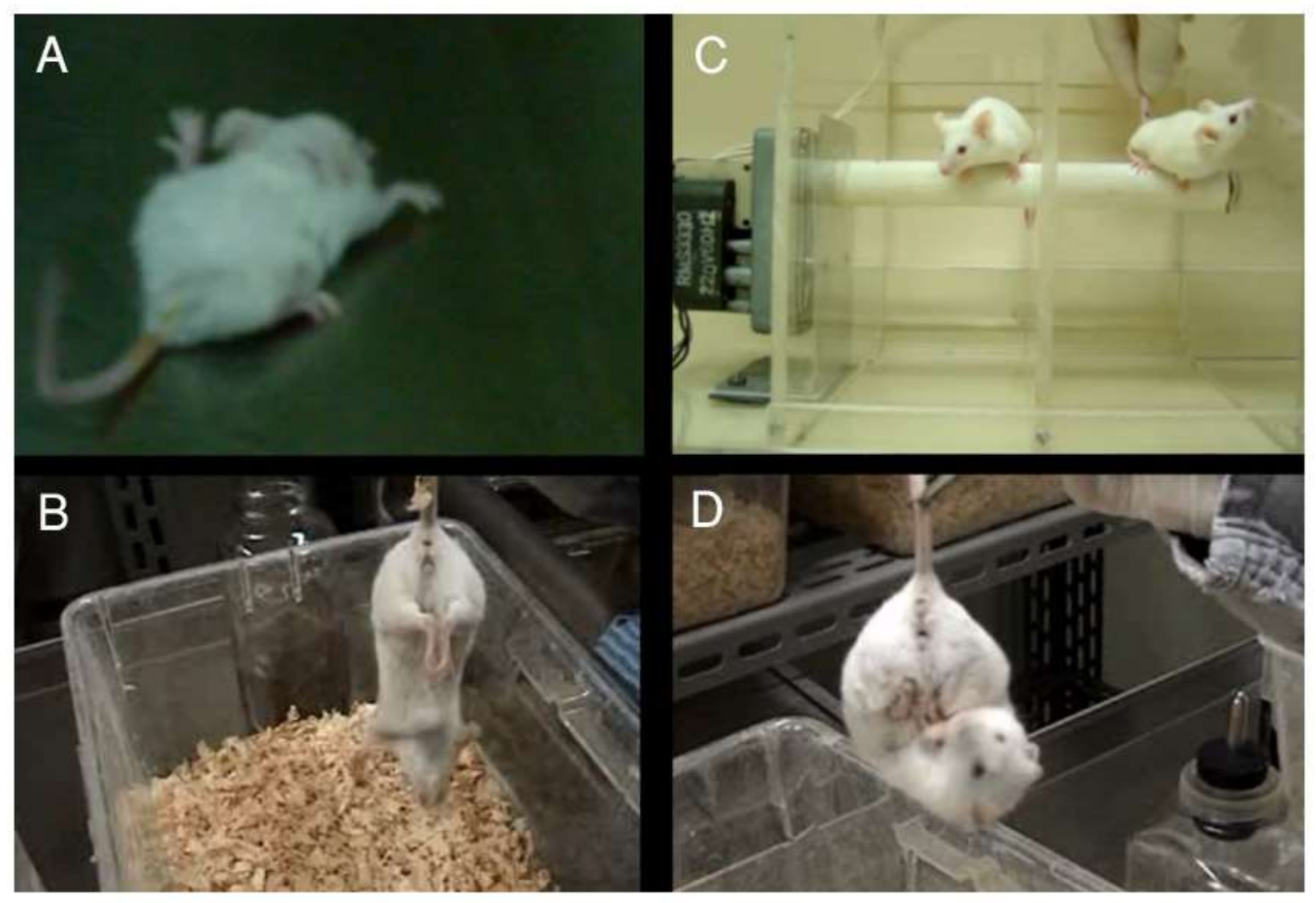

Figura 3.4 Fenótipos de alguns mutantes induzidos por ENU. O camundongo fraqueza (A) apresenta severo comprometimento motor pós-natal enquanto o camundongo batepalmas (B) realiza seu movimento estereotipado com os membros inferiores e posteriores. O camundongo equilíbrio (C) não se sustenta no rotarod enquanto o selvagem a sua esquerda não apresenta nenhuma dificuldade no teste. O camundongo cruzapernas (D), quando erguido pela cauda, se curva de maneira ventral cruzando os membros inferiores e superiores. Fotografias cedidas pela Dra. Massironi. 


\section{CAPÍTULO 4 - DESENVOLVIMENTO DE UMA FERRAMENTA PARA ANÁLISE DO PADRÃO DE MUTAÇÕES PONTUAIS}

\subsection{Introdução}

O genoma é um alvo constante de alterações vindas de metabólitos celulares endógenos, agentes mutagênicos externos e da própria instabilidade química espontânea do DNA. Dessa forma, mecanismos moleculares de reparo de danos ao DNA se desenvolveram ao longo da evolução para corrigir esses danos de maneira rápida e eficaz. Porém, a própria vida depende de um equilíbrio fino e dinâmico da diversidade promovida pela mutação. Na maioria das células somáticas, o acúmulo de mutações é danoso para o ser vivo, levando a processos associados à morte celular, envelhecimento e câncer (MENCK; MUNFORD, 2014). Porém, em alguns tipos de células somáticas, como células do sistema imune, o acúmulo de mutações em loci específicos gera diversidade de receptores e anticorpos para reconhecer patógenos, por exemplo (revisado por TENG; PAPAVASILIOU, 2007). Em células germinativas, o acúmulo de mutações também pode ser danoso, gerando alterações que podem levar a síndromes hereditárias (ANTONARAKIS; BECKMANN, 2006), mas ao mesmo tempo a mutação é considerada nesse contexto a fonte primária de diversidade necessária para processos adaptativos dos seres vivos.

Esse equilíbrio fino entre mudança e permanência é um dos segredos para a manutenção da vida. Entender esse balanço envolvendo a natureza dupla da mutação é essencial para compreender importantes mecanismos biológicos e solucionar importantes desafios na saúde humana, ecologia, conservação ambiental e na agricultura. Antes da era de genômica em larga escala, a maioria dos estudos de mutagênese era restrito a pequenas sequências e poucos genes, por exemplo TP53, o gene que codifica a proteína p53 (GLAZKO; MILANESI; ROGOZIN, 1998; ROGOZIN et al., 2003). A genômica tem contribuído muito para o entendimento dessas questões, com o uso de tecnologias de sequenciamento cada vez mais baratas e rápidas (KOBOLDT et al., 2013).

A maioria das análises em larga escala de identificação de mutações é oriunda de análises de ressequenciamento, que consiste no alinhamento de leituras à um genoma referência e a posterior chamada de variações. Esse tipo de análise é 
normalmente utilizado para a identificação de trocas de um único nucleotídeo, que podem estar associadas a patologias específicas. Portanto, o objetivo principal é quase sempre identificar o impacto de variantes raras no produto gênico associado, e por consequência, associá-lo ao fenótipo (DO; KATHIRESAN; ABECASIS, 2012). Dependendo do estudo em questão, no entanto, a avaliação do padrão de mutação global pode ser muito relevante. Um exemplo é a identificação de padrões de mutações somáticas em câncer (ALEXANDROV et al., 2013a, 2013b). Foram descobertas assinaturas mutagênicas específicas para vários tipos de câncer, como o câncer de mama (NIK-ZAINAL et al., 2012), através da caracterização das trocas e da sequência contexto das mutações pontuais utilizando banco de dados de mutações somáticas de vários pacientes. Embora algumas dessas assinaturas sejam específicas e possam ser úteis em termos de diagnóstico, elas indicam alguns padrões que podem estar associados à processo de reparo específicos e a regiões enriquecidas em mutações (ALEXANDROV et al., 2013b). A identificação desses padrões pode revelar as bases genéticas de transformação maligna e indicar formas de tratamento específicas e eficientes.

Os processos mutagênicos estão historicamente muito associados ao estudo do câncer, porém estudos de análise do padrão de mutações em outras situações e outros organismos são muito importantes. Dentre esses estudos destacamos, por exemplo, a avaliação do impacto global de agentes mutagênicos no genoma (POON et al., 2014), seleção e aquisição de resistência a medicamentos por bactérias (LÁZÁR et al., 2014), toxicogenômica (BESARATINIA et al., 2012) e estudos ecológicos de adaptação em populações (STAPLEY et al., 2010). A ferramenta woland se encaixa justamente nesse contexto, fornecendo um tipo de análise voltado para a identificação de padrões de mutações em diferentes tipos de dados de ressequenciamento, independentemente do organismo e plataforma de obtenção dos dados, e que ofereça diferentes análises do processo e impacto das mutações pontuais no objeto de estudo. 


\section{CONCLUSÕES E CONSIDERAÇÕES FINAIS}

O surgimento e o estabelecimento das tecnologias de sequenciamento NGS possibilitaram um salto qualitativo e quantitativo enorme em genômica. Porém, um dos grandes desafios é justamente a interpretação dos dados em um contexto biológico. Dessa forma, o presente trabalho teve como objetivo utilizar o sequenciamento de exomas para a caracterização de variantes genéticas em exomas de camundongos, desenvolvendo estratégias robustas para análise e interpretação desses dados.

Primeiramente, estabelecemos uma estratégia de sequenciamento com otimização de custos que possibilitou a obtenção de uma quantidade de leituras suficiente para a obtenção de cobertura superior a 70X, em média, do exoma de duas linhagens isogênicas mantidas pelo ICB, e de 7 camundongos mutantes. Para as linhagens isogênicas, foi descartada a possiblidade de contaminação cruzada com outras linhagens isogênicas. Além disso, o sequenciamento do exoma revelou que a linhagem C57BL/6ICBI é mais próxima da linhagem C57BL/6NJ, proveniente do $\mathrm{NIH}$, e não da sublinhagem C57BL/6J, proveniente da JAX. Já a linhagem BALB/c é bem próxima a sublinhagem BALB/cJ. Os SNVs novos detectados nas sublinhagens do ICB constituem uma valiosa fonte de informação para toda a comunidade científica usuária dos camundongos do ICB.

Em relação aos camundongos mutantes induzidos por ENU, foi desenvolvida uma estratégia de filtragem para seleção de variantes potencialmente causadoras dos fenótipos observados. Essa estratégia possibilitou a seleção de candidatos para todos os mutantes avaliados, com alta taxa de validação por sequenciamento Sanger. Análises de impacto funcional dessas variantes indicaram interessantes genes candidatos, principalmente para os mutantes bate palmas, equilíbrio, atáxico-1, fraqueza e careca.

Em resumo, acreditamos que o trabalho traga contribuições valiosas tanto para os usuários das linhagens isogênicas do ICB bem como incentivar a continuidade de estudos funcionais para os mutantes induzidos por ENU, pelos grupos colaboradores. Além disso, também acreditamos que o desenvolvimento de uma ferramenta de bioinformática aberta de análise do padrão de mutações possa também contribuir para o entendimento e para a formulação de novas hipóteses de processos de mutagênese. 


\section{REFERÊNCIAS}

1000GENOMES. A global reference for human genetic variation. Nature, v. 526, p. 6874, 2015.

ADZHUBEI, I.; JORDAN, D.; SUNYAEV, S. Predicting Functional Effect of Human Missense Mutations Using PolyPhen-2. Current Protocols in Human Genetics, v. 2, 2013.

ALEXANDROV, L. B. et al. Deciphering Signatures of Mutational Processes Operative in Human Cancer. Cell Reports, v. 3, n. 1, p. 246-259, 2013 b.

ALEXANDROV, L. B. et al. Signatures of mutational processes in human cancer. Nature, v. 500, n. 7463, p. 415-421, 2013a.

ALEXANDROV, L.B.; NIK-ZAINAL, S.; WEDGE, D.C.; CAMPBELL, P.J., STRATTON, M.R. Deciphering signatures of mutational processes operative in human cancer. Cell Reports, v. 1, n.3, p. 246-259, 2013.

ALTMAN, P.; KATZ, D. Inbred and Genetically Defined Strains of Laboratory Animals, Part 2, Hamster, Guinea Pig, Rabbit and Chicken. Bethesda, MD: Federation of American Societies for Experimental Biology, 1979.

AMBERGER, J. S. et al. OMIM . org: Online Mendelian Inheritance in Man ( OMIM R ), an online catalog of human genes and genetic disorders. Nucleic Acids Research, v. 43, n. November 2014, p. 789-798, 2015.

ANTONARAKIS, S. E.; BECKMANN, J. S. Focus on Monogenic Disorders. Nature reviews. Genetics, v. 7, n. April, p. 277-282, 2006.

ARNOLD, C. N. et al. ENU-induced phenovariance in mice: inferences from 587 mutations. BMC research notes, v. 5, n. 1, p. 577, jan. 2012.

ARNOLD, C. N. et al. Rapid identification of a disease allele in mouse through whole genome sequencing and bulk segregation analysis. Genetics, v. 187, n. 3, p. 633-41, mar. 2011.

ASAN et al. Comprehensive comparison of three commercial human whole-exome capture platforms. Genome biology, v. 12, n. 9, p. R95, jan. 2011.

BABUSYTE, A. et al. Biogenic amines activate blood leukocytes via trace amineassociated receptors TAAR1 and TAAR2. Journal of Leukocyte Biology, v. 93, n. 3, p. 387-394, 2013.

BAILEY, D. Sources of subline divergence and their relative importance for sublines of six major inbred strains of mice. In: Origins of Inbred Mice. New York, NY: ed. Morse III HC, 1978.

BANKS, G. et al. Neurobiology of Aging Genetic background in $\mathrm{fl}$ uences age-related decline in visual and nonvisual retinal responses, circadian rhythms, and sleep q. NBA, v. 36, n. 1, p. 380-393, 2015. 
BARBA, M.; CZOSNEK, H.; HADIDI, A. Historical perspective, development and applications of next-generation sequencing in plant virology. Viruses, v. 6, n. 1, p. 106136, 2013.

BARBARIC, I.; WELLS, S. Spectrum of ENU-induced mutations in phenotype-driven and gene-driven screens in the mouse. Molecular Mutagenesis, v. 142, n. December 2006, p. 124-142, 2007.

BATESON, W.; MENDEL, G. Mendel's principles of heredity. Cambridge: Cambridge: University Press, 1909, 1909.

BEAUSOLEIL, S. et al. Survey of Activated FLT3 Signaling in Leukemia. PloS one, v. 6, n. 4, p. 1-10, 2011.

BECK, J. A et al. Genealogies of mouse inbred strains. Nature genetics, v. 24, n. 1, p. 23-5, jan. 2000.

BEIER, D. R.; HERRON, B. J. Genetic mapping and ENU mutagenesis. Genetica, v. 122, n. 1, p. 65-69, 2004.

BELKNAP, J. K. et al. Voluntary consumption of morphine in 15 inbred mouse strains. Psychopharmacology, v. 112, n. 2-3, p. 352-358, 1993.

BESARATINIA, A. et al. A high-throughput next-generation sequencing-based method for detecting the mutational fingerprint of carcinogens. Nucleic Acids Research, v. 40, n. 15, p. e116-e116, 2012.

BILGÜVAR, K. et al. Whole-exome sequencing identifies recessive WDR62 mutations in severe brain malformations. Nature, v. 467, n. 7312, p. 207-210, 2010.

BJORNSSON, H. T. et al. Histone deacetylase inhibition rescues structural and functional brain deficits in a mouse model of Kabuki syndrome. Science translational medicine, v. 135, 2014.

BÖGERSHAUSEN, N.; WOLLNIK, B. Unmasking Kabuki syndrome. Clinical Genetics, v. 83, n. 3, p. 201-211, 2013.

BOGUE, M. A.; CHURCHILL, G. A.; CHESLER, E. J. Collaborative Cross and Diversity Outbred data resources in the Mouse Phenome Database. Mammalian genome: official journal of the International Mammalian Genome Society, v. 26, n. 9, p. 511520, 2015.

BOLES, M. K. et al. Discovery of candidate disease genes in ENU-induced mouse mutants by large-scale sequencing, including a splice-site mutation in nucleoredoxin. PLoS Genetics, v. 5, n. 12, 2009.

BOUABE, H.; OKKENHAUG, K. Europe PMC Funders Group Gene Targeting in Mice : a Review. Methods in Molecular Biology, p. 315-336, 2015.

BOUCHERIE. C.; BOUTIN, C.; JOSSIN, Y., SCHAKMAN, O.; GOFFINET, A.M.; RIS, L.; GAILLY, P.; TISSIR, F. Neural progenitor fate decisions defects, cortical hypoplasia and behavioral impairment in Celsr1-deficient mice. Mol Psychiatry, In Press, 2017. 
BROWN, S. D. M. et al. The functional annotation of mammalian genomes: the challenge of phenotyping. Annual review of genetics, v. 43, p. 305-33, 2009.

BULL, K. R. et al. Unlocking the bottleneck in forward genetics using whole-genome sequencing and identity by descent to isolate causative mutations. PLoS genetics, v. 9, n. 1, p. e1003219, jan. 2013.

BUSH, W. S.; MOORE, J. H. Chapter 11: Genome-Wide Association Studies. PLoS Biology, v. 8, n. 12, 2012.

CARUANA, G. et al. Genome-wide ENU mutagenesis in combination with high density SNP analysis and exome sequencing provides rapid identification of novel mouse models of developmental disease. Plos one, v. 8, n. 3, p. e55429, jan. 2013.

CASELLAS, J. Inbred mouse strains and genetic stability: a review. Animal, v. 5, n. 1, p. $1-7,2011$.

CASELLAS, J.; MEDRANO, J. F. Within-Generation Mutation Variance for Litter Size in Inbred Mice. v. 2155, n. August, p. 2147-2155, 2008.

CHEN, E. Y. et al. Enrichr: interactive and collaborative HTML5 gene list enrichment analysis tool. BMC bioinformatics, v. 14, p. 128, 2013.

CHHANGAWALA, $\mathrm{S}$. et al. The impact of read length on quantification of differentially expressed genes and splice junction detection. Genome Biology, v. 16, n. 1, p. 131, 2015.

CHOI, Y.; CHAN, A. P. PROVEAN web server: A tool to predict the functional effect of amino acid substitutions and indels. Bioinformatics, v. 31, n. 16, p. 2745-2747, 2015.

CHOI, Y.; CHAN, A. P. PROVEAN web server: A tool to predict the functional effect of amino acid substitutions and indels. Bioinformatics, v. 31, n. 16, p. 2745-2747, 2015.

$\mathrm{CHURCH}$, D. M. et al. Lineage-Specific Biology Revealed by a Finished Genome Assembly of the Mouse. PLoS Biology, v. 7, n. 5, p. e1000112, 2009.

CLARK, M. J. et al. Performance comparison of exome DNA sequencing technologies. Nature biotechnology, v. 29, n. 10, p. 908-14, out. 2011.

COLETTI, D. et al. Substrains of inbred mice differ in their physical activity as a behavior. The Scientific World Journal, v. 2013, 2013.

COOPER, D. N. et al. On the sequence-directed nature of human gene mutation The role of genomic architecture and the local DNA sequence environment in mediating gene mutations underlying human inherited disease. Human Mutation, v. 32, n. 10, p. 1075-1099, 2011.

CORDES, S. P. N -Ethyl- N -Nitrosourea Mutagenesis: Boarding the Mouse Mutant Express. Microbiology and molecular biology reviews, v. 69, n. 3, p. 426-439, 2005.

CROLLIUS, H. R. et al. Estimate of human gene number provided by genome- wide analysis using Tetraodon nigroviridis DNA sequence. v. 25, n. june, p. 235-238, 2000. 
DAGLEY, L. F. et al. Discovery of novel disease-specific and membrane-associated candidate markers in a mouse model of multiple sclerosis. Molecular \& cellular proteomics : MCP, v. 13, n. 3, p. 679-700, 2014.

DANECEK, P. et al. The variant call format and VCFtools. Bioinformatics (Oxford, England), v. 27, n. 15, p. 2156-8, 1 ago. 2011.

DAVIS, W. M.; KING, W. T.; BABBINI, M. Placebo effect of saline on locomotor activity in several strains of mice. Journal of pharmaceutical sciences, v. 56, n. 10, p. 13471349, out. 1967.

DE SOUZA, T. A.; IENNE, S. Capítulo 11: Sequenciamento de DNA. In: Biologia Molecular, Editor: Nancy Rebouças, submetido. Sao Paulo: Editora Atheneu, 2018.

DERDAK, S. et al. Genomic characterization of mutant laboratory mouse strains by exome sequencing and annotation lift-over. BMC genomics, v. 16, p. 351, 2015.

DIWAN, B. A.; BLACKMAN, K. E. Differential susceptibility of 3 sublines of C57BL/6 mice to the induction of colorectal tumors by 1,2-dimethyl-hydrazine. Cancer Letters, v. 9, p. 111-115, 1980.

DO, R.; KATHIRESAN, S.; ABECASIS, G. R. Exome sequencing and complex disease: Practical aspects of rare variant association studies. Human Molecular Genetics, v. 21, n. R1, p. 1-9, 2012.

DORAN, A. G. et al. Deep genome sequencing and variation analysis of 13 inbred mouse strains defines candidate phenotypic alleles, private variation and homozygous truncating mutations. Genome Biology, p. 1-16, 2016.

EISSENBERG, J. C.; SHILATIFARD, A. Histone H3 lysine $4 \mathrm{H} 3 \mathrm{~K} 4$ methylation in development and differentiation. Developmental Biology, v. 339, n. 2, p. 240-249, 2010.

ENCODE. An integrated encyclopedia of DNA elements in the human genome. Nature, v. 489, p. 57-74, 2012.

ENDERS, A. et al. Finding new immune regulatory genes by ENU mutagenesis. Journal of Translational Medicine, v. 10, n. Suppl 3, p. I6, 2012.

EPPIG, J. T. et al. Mouse Genome Informatics ( $\mathrm{MGI}$ ): reflecting on 25 years. Mammalian Genome, v. 26, n. 7, p. 272-284, 2015.

ERMANN, J.; GLIMCHER, L. H. After GWAS: mice to the rescue? Current opinion in immunology, v. 24, n. 5, p. 564-70, out. 2012.

FAIRFIELD, $\mathrm{H}$. et al. Exome sequencing reveals pathogenic mutations in 91 strains of mice with Mendelian disorders. Genome Research, v. 25, p. 948-957, 2015.

FAIRFIELD, $\mathrm{H}$. et al. Mutation discovery in mice by whole exome sequencing. Genome biology, v. 12, n. 9, p. R86, 2011. 
FANG, $Y$. et al. Nonsense-mediated mRNA decay of collagen -emerging complexity in RNA surveillance mechanisms. Journal of cell science, v. 126, n. Pt 12, p. 2551-60, 2013.

FARRELL, A. et al. Whole genome profiling of spontaneous and chemically induced mutations in Toxoplasma gondii. BMC genomics, v. 15, n. 1, p. 354, 2014.

FERRIER, A. et al. Transgenic expression of neuronal dystonin isoform 2 partially rescues the disease phenotype of the dystonia musculorum mouse model of hereditary sensory autonomic neuropathy VI. Human Molecular Genetics, v. 23, n. 10, p. 2694$2710,2014$.

FESTING, M. Origins and characteristics of inbred strains of mice. 3rd. ed. Oxford: Oxford University Press, 1996.

FLINT, J.; MACKAY, T. F. C. Genetic architecture of quantitative traits in mice, flies , and humans. Genome research, v. 19, p. 723-733, 2009.

FONTAINE, D. A.; DAVIS, D. B. Attention to Background Strain Is Essential for Metabolic Research: C57BL / 6 and the International Knockout Mouse Consortium. Diabetes, v. 65, n. January, p. 25-33, 2016.

FRAZER, K. A. et al. A sequence-based variation map of 8.27 million SNPs in inbred mouse strains. Nature, v. 448, n. 7157, p. 1050-1053, 2007.

FULLER, J. L. Measurement of alcohol preference in genetic experiments. Journal of comparative and physiological psychology, v. 57, p. 85-88, fev. 1964.

GAO, Q. et al. A systematic evaluation of hybridization-based mouse exome capture system. BMC genomics, v. 14, n. 1, p. 492, 21 jul. 2013.

GARROD, A. E. The Incidence of Alkaptonuria: A Study in Chemical Individuality. Lancet, v. ii, p. 1616-1620, 1902.

GEHRING, J.S.; FISCHER, B.; LAWRENCE, M.; HUBER, W. SomaticSignatures: inferring mutational signatures from single-nucleotide variants. Bioinformatics, v. 22, n. 31, p. 2673-3675, 2015.

GHOSH, S.; BOUCHARD, C. Convergence between biological, behavioural and genetic determinants of obesity. Nature Publishing Group, 2017.

GLANT, T. et al. Variations in Susceptibility to Proteoglycan-Induced Arthritis and Spondylitis Among $\mathrm{C} 3 \mathrm{H}$ Substrains of Mice. Arthirits \& rheumatism, v. 44, n. 3, p. 682-692, 2001.

GLASER, S. et al. Multiple epigenetic maintenance factors implicated by the loss of MII2 in mouse development. Development (Cambridge, England), v. 133, n. 8, p. 1423-32, abr. 2006.

GLAZKO, G. B.; MILANESI, L.; ROGOZIN, I. B. The subclass approach for mutational spectrum analysis: application of the SEM algorithm. Journal of theoretical biology, v. 192, n. 4, p. 475-487, 1998. 
GOIOS, A. et al. mtDNA phylogeny and evolution of laboratory mouse strains. Genome research, v. 17, p. 293-298, 2007.

GONDO, Y. Now and future of mouse mutagenesis for human disease models. Journal of Genetics and Genomics, v. 37, n. 9, p. 559-572, 2010.

GREEN, E. L. Biology of the Laboratory Mouse. Second Edi ed. New York: Dover Publications, 1966.

GREENFIELD, E. A. Generating Monoclonal Antibodies. Second Edi ed. [s.I.] Cold Spring Harbor Laboratory Press, 2014.

GUÉNET, J. et al. Genetics of the Mouse. Berlin Heidelberg: Springer-Verlag Berlin Heidelberg, 2015.

GUÉNET, J. L. The mouse genome. Genome Research, v. 15, p. 1729-1740, 2005.

GUO, C. et al. Global identification of MLL2-targeted loci reveals MLL2's role in diverse signaling pathways. Proceedings of the National Academy of Sciences of the United States of America, 23 out. 2012.

HAMAMY, H. Consanguineous marriages Preconception consultation in primary health care settings. Journal of Community Genetics, v. 3, p. 185-192, 2012.

HAMAMY, $\mathrm{H}$. et al. Consanguineous marriages, pearls and perils: Geneva. Genetics in Medicine, v. 13, n. 9, 2011.

HANSEN, C. T. Catalog of NIH rodents. Bethesda: National Institutes of Health, 1973.

HEARD, E. et al. Ten years of genetics and genomics: what have we achieved and where are we heading? Nature Publishing Group, v. 11, n. 10, p. 723-733, 2010.

HERRON, B. J. et al. Efficient generation and mapping of recessive developmental mutations using ENU mutagenesis. Nature genetics, v. 30, n. february, p. 185-189, 2002.

HESTON, W. E.; VLAHAKIS, G. Alveolar nodules in various combinations of the mouse inbred strains and the different lines of the mammary tumor virus. International Journal of Cancer, v. 148, p. 141-148, 1971.

HOAG, W. G. SPONTANEOUS CANCER IN MICE. Annals of the New York Academy of Sciences, v. 108, p. 805-831, nov. 1963.

IKEHATA, $\mathrm{H}$. et al. Remarkable induction of UV-signature mutations at the 3'-cytosine of dipyrimidine sites except at 5'-TCG-3' in the UVB-exposed skin epidermis of xeroderma pigmentosum variant model mice. DNA Repair, v. 22, p. 112-122, 2014.

INGELMAN-SUNDBERG, M. et al. Special Section on Epigenetic Regulation of Drug Metabolizing Enzymes and Transporters - Symposium Report Potential Role of Epigenetic Mechanisms in the Regulation of Drug Metabolism and Transport. Drug Metabolism and Disposition, p. 1725-1731, 2013. 
INUI, S.; ITAMI, S. Androgen actions on the human hair follicle: perspectives. Experimental Dermatology, v. 22, n. 3, p. 168-171, 2013.

JUSTICE, M. J. et al. Mouse ENU Mutagenesis. Human Molecular Genetics, v. 8, n. 10, p. 1955-1963, 1999.

JUSTICE, M. J.; DHILLON, P. Using the mouse to model human disease: increasing validity and reproducibility. Disease Models \& Mechanisms, v. 9, p. 101-103, 2016.

KEANE, T. M. et al. Mouse genomic variation and its effect on phenotypes and gene regulation. Nature, v. 477, n. 7364, p. 289-294, 2011.

KELLIS, M. et al. Defining functional DNA elements in the human genome. PNAS, v. 111, n. 17, p. 6131-6138, 2014.

KERN, M. et al. Biochemical and Biophysical Research Communications C57BL / 6JRj mice are protected against diet induced obesity ( DIO ). Biochemical and Biophysical Research Communications, v. 417, n. 2, p. 717-720, 2012.

KHISTI, R. T. et al. Characterization of the ethanol-deprivation effect in substrains of C57BL / 6 mice. Alcohol, v. 40, p. 119-126, 2006.

KILE, B. T.; HILTON, D. J. The art and design of genetic screens: mouse. Nature Reviews Genetics, v. 6, n. 7, p. 557-567, 2005.

KOBOLDT, D. C. et al. Review The Next-Generation Sequencing Revolution and Its Impact on Genomics. Cell, v. 155, n. 1, p. 27-38, 2013.

KOELSCH, B.U.; KINDLER-RÖHRBORN, A. Neuro-oncogenesis induced by nitroso compounds in rodents and strain-specific genetic modifiers of predisposition. In: CNS Cancer: Models, Markers, Prognostic Factors, Targets, and Therapeutic Approaches. Ed: Erwin G. Van Meir. Springer Science \& Business Media, 2009.

KOKITSU-NAKATA, N. M. et al. Analysis of MLL2 gene in the first Brazilian family with Kabuki syndrome. American journal of medical genetics. Part A, ago. 2012.

KRAFT, M. et al. Disruption of the histone acetyltransferase MYST4 leads to a noonan syndrome-like phenotype and hyperactivated MAPK signaling in humans and mice. Journal of Clinical Investigation, v. 121, n. 9, p. 3479-3491, 2011.

KUMAR, P.; HENIKOFF, S.; NG, P. C. Predicting the effects of coding non-synonymous variants on protein function using the SIFT algorithm. Nature protocols, v. 4, n. 8, p. 1073-1082, 2009.

KURE, E.; ANTONIO, F. A molecular pathway analysis stresses the role of inflammation and oxidative stress towards cognition in schizophrenia. Journal of Neural Transmission, v. 124, n. 7, p. 765-774, 2017.

LANGMEAD, B. Alignment with Bowtie. Current Protocols in Bioinformatics, p. 1-24, 2011.

LÁZÁR, V. et al. Genome-wide analysis captures the determinants of the antibiotic cross-resistance interaction network. Nat Commun, v. 5, 2014. 
LE, A. D. et al. Alcohol consumption by C57BL/6, BALB/C, and DBA/2 mice in a limited access paradigm. Pharmacology, biochemistry, and behavior, v. 47, n. 2, p. 375378, fev. 1994.

LEVY, S. et al. The Diploid Genome Sequence of an Individual Human. PLoS Biology, v. 5, n. 10, p. 2113-2144, 2007.

LIFETECHNOLOGIES. LifeScope TM Genomic Analysis Software 2 . 5 Command Shell. n. 4471875, 2011.

LIM, K. H.; FAIRBROTHER, W. G. Spliceman - a computational web server that predicts sequence variations in pre-mRNA splicing. Bioinformatics, v. 28, n. 7, p. 1031-1032, 2012.

LINDE, L. et al. Nonsense-mediated mRNA decay affects nonsense transcript levels and governs response of cystic fibrosis patients to gentamicin. Journal of Clinical Investigation, v. 117, n. 3, p. 683-692, 2007.

LIU, Q. et al. Steps to ensure accuracy in genotype and SNP calling from Illumina sequencing data. BMC genomics, v. 13 Suppl 8, n. Suppl 8, p. S8, jan. 2012.

LU, Z.; KIPNIS, J. Thrombospondin 1--a key astrocyte-derived neurogenic factor. The FASEB Journal, v. 24, n. 6, p. 1925-1934, 2010.

LYNCH, M. Evolution of the mutation rate. Trends in Genetics, v. 26, n. 8, p. 345-352, 2010.

MACARIO, A. J.; STAHL, W.; MILLER, R. Lymphocyte subpopulations and function in chronic murine toxoplasmosis. Clinical and experimental immunology, v. 41, n. 3, p. 415-422, set. 1980.

MAKRYTHANASIS, P. et al. MLL2 mutation detection in 86 patients with Kabuki syndrome: a genotype-phenotype study. Clinical genetics, v. 84, n. 6, p. 539-45, dez. 2013.

MANDILLO, S. et al. Reliability, robustness, and reproducibility in mouse behavioral phenotyping: a cross-laboratory study. Physiological Genetics, v. 34, p. 243-255, 2008.

MARDIS, E. R. DNA sequencing technologies: 2006-2016. Nature Protocols, v. 12, n. 2, p. 213-218, 2017.

MARDIS, E. R. Next-Generation DNA Sequencing Methods. Annual Reviews Genomics and Human Genetics, v. 9, p. 387-402, 2008.

MARDIS, E. R. Next-Generation Sequencing Platforms. Annual Reviews Genomics and Human Genetics, v. 6, p. 287-303, 2013.

MARTELOTTO, L. G. et al. Benchmarking mutation effect prediction algorithms using functionally validated cancer-related missense mutations. Genome Biology, v. 15, n. 10, p. 484, 2014. 
MASSIRONI, S. M. G. et al. Inducing mutations in the mouse genome with the chemical mutagen ethylnitrosourea. Brazilian journal of medical and biological research, $v$. 39, n. 9, p. 1217-26, set. 2006.

MASUMURA, K. et al. Dose-dependent de novo germline mutations detected by wholeexome sequencing in progeny of ENU-treated male gpt delta mice. Mutation Research - Genetic Toxicology and Environmental Mutagenesis, v. 810, p. 30-39, 2016.

MATSUO, $\mathrm{H}$. et al. Effects of time of $\mathrm{L}$-ornithine administration on the diurnal rhythms of plasma growth hormone, melatonin , and corticosterone levels in mice. Chronobiology International, p. 1-10, 2014.

MEKADA, K. et al. Genetic differences among C57BL/6 substrains. Experimental animals / Japanese Association for Laboratory Animal Science, v. 58, n. 2, p. 1419, abr. 2009.

MENCK, C. F.; MUNFORD, V. DNA repair diseases: what do they tell us about cancer and aging? Genetics and Molecular Biology, v. 37, n. 1, p. 220-233, 2014.

MGS. Initial sequencing and comparative analysis of the mouse genome. Nature, v. 420, n. December, p. 520-562, 2002.

MONROY-OSTRIA, A. et al. Infection of BALB/C, C57B1/6 mice and F1 hybrid CB6F1 mice with strains of Leishmania mexicana isolated from Mexican patients with localized or diffuse cutaneous leishmaniasis. Archives of medical research, v. 25, n. 4, p. 401406, 1994.

MORAN, J. L. et al. Utilization of a whole genome SNP panel for efficient genetic mapping in the mouse. Genome research, p. 436-440, 2006.

MORESCO, E. M. Y.; LI, X.; BEUTLER, B. Going forward with genetics: recent technological advances and forward genetics in mice. The American journal of pathology, v. 182, n. 5, p. 1462-73, maio 2013.

MORITZ, A. et al. Akt-RSK-S6 kinase signaling networks activated by oncogenic receptor tyrosine kinases. Science signaling, v. 3, n. 136, p. ra64, jan. 2010.

MUNFORD, V. et al. A genetic cluster of patients with variant xeroderma pigmentosum with two different founder mutations *. British Journal of Dermatology, v. 176, p. 1270-1278, 2017.

NAGGERT, J. K. et al. Genomic analysis of the C57BL/Ks mouse strain. Mammalian Genome, v. 133, p. 131-133, 1995.

NAKAJIMA, K. et al. Exome sequencing in the knockin mice generated using the CRISPR/Cas system. Scientific Reports, v. 6, n. 1, p. 34703, 2016.

NGUYEN, N. et al. Random mutagenesis of the mouse genome: a strategy for discovering gene function and the molecular basis of disease. Gastrointestinal and Liver Physiology, v. 300, 2011. 
NICHOLSON, A. et al. Diet-induced obesity in two C57BL/6 substrains with intact or mutant nicotinamide nucleotide transhydrogenase (Nnt) gene. Obesity (Silver Spring, Md.), v. 18, n. 10, p. 1902-5, 2010.

NIK-ZAINAL, S. et al. Mutational processes molding the genomes of 21 breast cancers. Cell, v. 149, p. 979-993, 2012.

NOLAN, P. M.; HUGILL, A.; COX, R. D. ENU mutagenesis in the mouse: Application to human genetic disease. Briefings in Functional Genomics and Proteomics, v. 1, n. 3, p. 278-289, 2002.

NOVEROSKE, J. K.; WEBER, J. S.; JUSTICE, M. J. The mutagenic action of N-ethyl-Nnitrosourea in the mouse. Mammalian Genome, v. 483, p. 478-483, 2000.

OLIVEIRA, N. S. Caracterização fenotípica do camundongo mutante bate palmas induzido pelo agente mutagênico químico ENU ( $\mathrm{N}$ - Ethyl- $\mathrm{N}$ - Nitrosourea) como potencial modelo para a síndrome de Kabuki. [s.I.] Universidade de São Paulo, 2017.

OLIVER, P. L.; DAVIES, K. E. New insights into behaviour using mouse ENU mutagenesis. Human Molecular Genetics, v. 21, n. 1, p. 72-81, 2012.

PAIGEN, B. et al. Atherosclerosis Susceptibility Differences among Progenitors of Recombinant Inbred Strains of Mice. Arteiosclerosis, thrombosis and vascular biology, p. 316-323, 1990.

PASANIUC, B. et al. Extremely low-coverage sequencing and imputation increases power for genome-wide association studies. Nature genetics, v. 44, n. 6, p. 631-5, jun. 2012.

PATTON, E. E.; ZON, L. I. The art and design of genetic screens: zebrafish. Nature Reviews Genetics, v. 2, n. December, p. 956-966, 2001.

PETTITT, S. J. et al. Agouti C57BL / 6N embryonic stem cells for mouse genetic resources. Nature Publishing Group, v. 6, n. 7, p. 493-495, 2009.

PEVZNER, P. A.; TANG, H.; WATERMAN, M. S. An Eulerian path approach to DNA fragment assembly. PNAS, v. 98, n. 17, p. 9748-9753, 2001.

PGH. Initial sequencing and analysis of the human genome. Nature, v. 409, n. February, p. 860-921, 2001.

POON, S. et al. Mutation signatures of carcinogen exposure: genome-wide detection and new opportunities for cancer prevention. Genome Medicine, v. 6, n. 3, p. 24, 2014.

POPEJOY, A. B.; FULLERTON, S. M. Genomics is falling on diversity. Nature, v. 538, n. 161, p. $164,2016$.

POTTER, S. W.; MORRIS, J. E. Development of mouse embryos in hanging drop culture. The Anatomical record, v. 211, n. 1, p. 48-56, jan. 1985.

PRANCKEVIČIENE, E. et al. Challenges in exome analysis by LifeScope and its alternative computational pipelines. BMC Research Notes, p. 1-15, 2015. 
PREMSRIRUT, P. K. et al. Resource A Rapid and Scalable System for Studying Gene Function in Mice Using Conditional RNA Interference. Cell, v. 145, n. 1, p. 145-158, 2011.

RHODES, M. et al. A High-Resolution Microsatellite Map of the Mouse Genome. Genome research, p. 531-542, 1998.

RICHARDS, S. et al. Standards and guidelines for the interpretation of sequence variants: a joint consensus recommendation of the American College of Medical Genetics and Genomics and the Association for Molecular Pathology. Genetics in Medicine, v. 17, n. 5, p. 405-423, 2015.

RICHTER, S. H. et al. Effect of Population Heterogenization on the Reproducibility of Mouse Behavior: A Multi-Laboratory Study. PLoS ONE, v. 6, 2011.

RIEBER, N. et al. Coverage bias and sensitivity of variant calling for four whole-genome sequencing technologies. PloS One, v. 8, n. 6, p. e66621, jan. 2013.

ROGOZIN, I. B. et al. Computational analysis of mutation spectra. Briefings in bioinformatics, v. 4, n. 3, p. 210-227, 2003.

RONCHI, J. A et al. A spontaneous mutation in the nicotinamide nucleotide transhydrogenase gene of $\mathrm{C} 57 \mathrm{BL} / 6 \mathrm{~J}$ mice results in mitochondrial redox abnormalities. Free radical biology \& medicine, v. 63, p. 446-56, out. 2013.

ROSCIOLI, T. et al. Mutations in ISPD cause Walker-Warburg syndrome and defective glycosylation of $\alpha$-dystroglycan. Nature Genetics, v. 44, n. 5, p. 581-585, 2012.

ROTH, D. M. et al. Impact of anesthesia on cardiac function during echocardiography in mice. Heart and Circulatory Phisiology, v. 92161, p. 2134-2140, 2002.

ROWLAND, E. C.; LOZYKOWSKI, M. G.; MCCORMICK, T. S. Differential cardiac histopathology in inbred mouse strains chronically infected with Trypanosoma cruzi. The Journal of parasitology, v. 78, n. 6, p. 1059-1066, dez. 1992.

RUTHENBURG, A. J.; ALLIS, C. D.; WYSOCKA, J. Methylation of lysine 4 on histone H3: intricacy of writing and reading a single epigenetic mark. Molecular cell, v. 25, n. 1 , p. 15-30, 12 jan. 2007.

SALMELA, L. Correction of sequencing errors in a mixed set of reads. Bioinformatics, v. 26, n. 10, p. $1284-1290,2010$.

SAZER, S.; DASSO, M. The ran decathlon: multiple roles of Ran. Journal of cell science, v. 113 ( Pt 7, p. 1111-1118, 2000.

SCHAUB, M. A. et al. Linking disease associations with regulatory information in the human genome. Genome Research, v. 22, p. 1748-1759, 2012.

SCHWEINGRUBER, C. et al. Nonsense-mediated mRNA decay - Mechanisms of substrate mRNA recognition and degradation in mammalian cells. Biochimica et Biophysica Acta - Gene Regulatory Mechanisms, v. 1829, n. 6-7, p. 612-623, 2013. 
SEKHAR, C. et al. Performance comparison of four exome capture systems for deep sequencing Performance comparison of four exome capture systems for deep sequencing. BMC genomics, v. 15, n. 449, 2014.

$\mathrm{SHAO}, \mathrm{H}$. et al. Genetic architecture of complex traits: Large phenotypic effects and pervasive epistasis. PNAS, v. 105, n. 50, p. 19910-19914, 2008.

SHIBUYA, T.; MORIMOTO, K. A review of the genotoxicity of 1-ethyl-1-nitrosourea. Mutation research, v. 297, p. 3-38, 1993.

SIEVERS, F. et al. Fast, scalable generation of high-quality protein multiple sequence alignments using Clustal Omega. Molecular Systems Biology, v. 7, n. 1, p. 539-539, 2014.

SILVA E SILVA, D.A; GODARD, A.L.B. Mapeamento genético e estudo de genes candidatos para um modelo animal de doença neuromuscular. Dissertação de Mestrado, Instituto de Ciências Biológicas, Universidade Federal de Minas Gerais, 2012.

SIMON, M. M. et al. A comparative phenotypic and genomic analysis of C57BL / $6 \mathrm{~J}$ and C57BL / 6N mouse strains. Genome biology, p. 1-22, 2013.

SIMON, M. M. et al. Current strategies for mutation detection in phenotype-driven screens utilising next generation sequencing. Mammalian Genome, v. 26, n. 9, p. 486500, 2015.

SIMPSON, E. et al. Genetic variation among 129 substrains and its importance for targeted mutagenesis in mice. Nature genetics, v. 16, p. 19-27, 1997.

SITTIG, L. J. et al. Phenotypic instability between the near isogenic substrains BALB/CJ and BALB/cByJ. Mammalian genome: official journal of the International Mammalian Genome Society, v. 25, n. 11-12, p. 564-72, dez. 2014.

SNELL, G. D. Studies in Histocompatibility. The Nobel Lectures, n. December, 1980.

STAAHL, B. T. et al. Efficient genome editing in the mouse brain by local delivery of engineered Cas9 ribonucleoprotein complexes. Nature Publishing Group, n. August 2016, 2017.

STAPLEY, J. et al. Adaptation genomics: the next generation. Trends in ecology \& evolution, v. 25, n. 12, p. 705-12, dez. 2010.

STIEDL, O. et al. Strain and substrain differences in context- and tone-dependent fear conditioning of inbred mice. Behavioural Brain Research, v. 104, p. 1-12, 1999.

SUD, A. et al. Risk of Second Cancer in Hodgkin Lymphoma Survivors and Influence of Family History. Journal of Clinical Oncology, v. 35, n. 14, p. 1584-1591, 2017.

SUN, M. et al. Multiplex Chromosomal Exome Sequencing Accelerates Identification of ENU-Induced Mutations in the Mouse. G3 (Bethesda, Md.), v. 2, n. 1, p. 143-50, jan. 2012. 
TAKADA, T. et al. The ancestor of extant Japanese fancy mice contributed to the mosaic genomes of classical inbred strains. Genome research, v. 23, n. 8, p. 1329-38, ago. 2013.

TAKAHASI, K. R.; SAKURABA, Y.; GONDO, Y. Mutational pattern and frequency of induced nucleotide changes in mouse ENU mutagenesis. BMC molecular biology, v. 8, p. 52, jan. 2007.

TANG, S. et al. DiBayes: A SNP detection algorithm for next-generation dibase sequencing.http://www3.appliedbiosystems.com/cms/groups/mcb_marketing/documents /generaldocuments/cms_057817.pdf, 2008

TANISAWA, K. et al. Exome sequencing of senescence-accelerated mice (SAM) reveals deleterious mutations in degenerative disease-causing genes. BMC genomics, v. 14, p. 248, jan. 2013.

TENG, G.; PAPAVASILIOU, F. N. Immunoglobulin Somatic Hypermutation. Annu Rev Genet, v. 41, p. 107-120, 2007.

TEUSCHER, C. et al. A Common Immunoregulatory Locus Controls Susceptibility to Actively Induced Experimental Allergic Encephalomyelitis and Experimental Allergic Orchitis in BALB/c Mice. The Journal of Immunology, p. 2751-2756, 1998.

THOMPSON, W. R. The inheritance of behaviour: behavioural differences in fifteen mouse strains. Canadian Journal of Psychology, v. 7, p. 145-155, 1953.

TOYE, A. A. et al. A genetic and physiological study of impaired glucose homeostasis control in C57BL/6J mice. Diabetologia, v. 48, n. 4, p. 675-686, 2005.

ULMASOV, B. et al. Differences in the Degree of Cerulein-Induced Chronic Pancreatitis in C57BL / 6 Mouse Substrains Lead to New Insights in Identi fi cation of Potential Risk Factors in the Development of Chronic Pancreatitis. The American Journal of Pathology, v. 183, n. 3, p. 692-708, 2013.

VENTER, J. C. et al. The Sequence of the Human Genome. Science, v. 291, n. February, 2001.

VISSCHER, P. M. et al. Five Years of GWAS Discovery. The American Journal of Human Genetics, v. 90, n. 1, p. 7-24, 2012.

WALSH, T. et al. Whole exome sequencing and homozygosity mapping identify mutation in the cell polarity protein GPSM2 as the cause of nonsyndromic hearing loss DFNB82. American Journal of Human Genetics, v. 87, n. 1, p. 90-94, 2010.

WANG, K.; LI, M.; HAKONARSON, H. ANNOVAR: functional annotation of genetic variants from high-throughput sequencing data. Nucleic acids research, v. 38, n. 16, p. e164, set. 2010.

WANG, W.; CHEN, Z.; MAO, Z.; ZHANG, H.; DING, X.; CHEN, S.; ZHANG, X.; XU, R.; ZHU, B.; Nucleolar protein Spindlin1 recognizes H3K4 methylation and stimulates the expression of rRNA genes. EMBO Rep, v. 11, n. 12, p. 1160-1166, 2011. 
WARR, A. et al. Exome Sequencing: Current and Future Perspectives. G3 (Bethesda, Md.), v. 5, n. August, p. 1543-1550, 2015.

WEI, L. et al. Exome sequencing analysis of murine medulloblastoma models identifies WDR11 as a potential tumor suppressor in Group 3 tumors. Oncotarget, v. 8, n. 39, p. 64685-64697, 2017.

WEYDEN, L. VAN DER et al. The mouse genetics toolkit: revealing function and mechanism. Genome biology, v. 12, 2011.

WOTJAK, C. T. C57BLack / BOX? The importance of exact mouse strain nomenclature. Trends in Genetics, v. 19, n. 4, p. 183-184, 2003.

WYSOCKI, C. J.; WHITNEY, G.; TUCKER, D. Specific anosmia in the laboratory mouse. Behavior genetics, v. 7, n. 2, p. 171-188, mar. 1977.

YALCIN, B. et al. Next-generation sequencing of experimental mouse strains. Mammalian genome: official journal of the International Mammalian Genome Society, v. 23, n. 9-10, p. 490-8, 2012.

YANG, $\mathrm{H}$. et al. Subspecific origin and haplotype diversity in the laboratory mouse. Nature Genetics, v. 43, n. 7, p. 648-655, 2011.

YANG, L.; FARAONE, S.V.; ZHANG-JAMES, Y. Autism spectrum disorder traits in Slc9a9 knock-out mice. Am J Med Genet B Neuropsychiatr Genet, v. 3, p. 363-376, 2016.

YANG, Y. et al. Spontaneous deletion of epilepsy gene orthologs in a mutant mouse with a low electroconvulsive threshold. Human Molecular Genetics, v. 12, n. 9, p. 975984, 2003.

YOUNG, L. J.; HAMMOCK, E. A. D. On switches and knobs, microsatellites and monogamy. Trends in Genetics, v. 23, n. 5, p. 209-212, 2007.

ZENG, X.H.; YANG, C. XIA, X.M.; LIU, M.; LINGLE, C.J. SLO3 auxiliary subunit LRRC52 controls gating of sperm KSPER currents and is critical for normal fertility. PNAS, v.8, n.122, p. 2599-2604, 2015.

ZHANG, F.; LUPSKI, J. R. Non-coding genetic variants in human disease. Human Molecular Genetics, v. 24, n. July, p. 102-110, 2015.

ZHAO, Y. et al. MicroRNA-mediated repression of nonsense mRNAs. eLife, p. e03032, 2014.

ZURITA, E. et al. Genetic polymorphisms among C57BL/6 mouse inbred strains. Transgenic research, v. 20, n. 3, p. 481-9, jun. 2011. 